\title{
The Role of Diversification in the Pricing of Accruals QUALITY
}

by

$\mathrm{Yu} \mathrm{Hou}$

A thesis submitted in conformity with the requirements

for the degree of Doctor of Philosophy

Joseph L. Rotman School of Management

University of Toronto

Copyright (c) 2013 by Yu Hou 


\begin{abstract}
The Role of Diversification in the Pricing of Accruals Quality
\end{abstract}

\author{
Yu Hou \\ Doctor of Philosophy \\ Joseph L. Rotman School of Management \\ University of Toronto \\ 2013
}

A growing number of studies suggest that accounting information risk, primarily idiosyncratic in nature, can be diversified away in the capital market. In this dissertation, I show that accounting information risk, proxied by accruals quality, is priced even if it is entirely idiosyncratic. In particular, building on a model from the ambiguity literature, I demonstrate that (1) in an under-diversified market, idiosyncratic information risk is priced even if it is diversifiable, and (2) in a well-diversified market, idiosyncratic information risk is priced when information is subject to managers' discretion and thus ambiguous. The empirical results corroborate the predictions from the model. Specifically, although an association is observed between (unambiguous if risky) innate accruals quality and cost of capital, the association can be largely mitigated through diversification. However, diversification has little impact on the association between (ambiguous) discretionary accruals quality and cost of capital. Taken together, these findings strengthen our understanding of the fundamental role of accounting information as a basis for capital allocation. 


\section{Acknowledgements}

I am grateful to my supervisors, Jeffrey Callen and Gordon Richardson, for patiently guiding me through my doctoral studies; my dissertation committee members Partha Mohanram and Liyan Yang; and Inder Khurana (the external reviewer) for their excellent

comments and suggestions on my thesis. I am also greatly indebted to Ling Cen, Feng Chen, Gus De Franco, Alex Edwards and Aida Wahid for their counsel and support during the $\mathrm{PhD}$ and on the job market.

I owe special gratitude to my friends and colleagues in the $\mathrm{PhD}$ program for their help and advice during the past five years, in particular to Yiwei Dou, Xiaohua Fang, Na Li, Yanju Liu, Matt Lyle, Jianfu Wang, Kevin Veenstra, Xiaofei Zhao, and Youli Zou.

Finally, I dedicate this dissertation to my family; specifically, to my wife Xiaoyu Huang and to my parents as I could not have made it without their love and support. 


\section{Contents}

Page

$\begin{array}{ll}\text { Abstract } & \text { ii }\end{array}$

$\begin{array}{ll}\text { Acknowledgements } & \text { iii }\end{array}$

Table of contents

List of Tables $\quad$ vi

1 Introduction 1

2 Literature Review $\quad 5$

2.1 Information Risk and Cost of Capital . . . . . . . . . . . . 5

2.1 .1 Analytic Work ................... 5

$2.1 .2 \quad$ Empirical Evidence $\ldots \ldots \ldots \ldots \ldots$

2.2 Ambiguity . . . . . . . . . . . . . . . 9

2.2.1 Subjective Expected Utility Theory . . . . . . . . . . . . . 10

2.2.2 Decision Making under Ambiguity . . . . . . . . . . . . . . . 12

2.2.3 Models of Ambiguity Averse Preferences . . . . . . . . . . . . . 14

2.2.4 Ambiguity and Capital Market _. . . . . . . . . . . . 16

3 Hypotheses Development $\quad 19$

3.1 The Epstein-Schneider Model . . . . . . . . . . . . . . . . . . . . . . 19 
3.2 Hypotheses Development . . . . . . . . . . . . . . . . . . 22

4 Research Design $\quad 24$

4.1 Measuring Accruals Quality .................. 24

4.2 Measuring the Implied Cost of Capital . . . . . . . . . . . . . . . . 25

4.3 Measuring the Extent of Diversification . . . . . . . . . . . . . 26

5 Empirical Results $\quad 29$

5.1 Sample and Descriptive Statistics . . . . . . . . . . . . . . . . 29

5.2 Portfolio Analysis . . . . . . . . . . . . . . . . . . . 31

5.3 Multivariate Analysis . . . . . . . . . . . . . . . . 33

5.3.1 The Association Between Accruals Quality and Cost of Capital . 33

5.3.2 The Influence of Diversification on the Pricing of Accruals Quality 35

6 Robustness Checks 38

6.1 De-biased Cost of Capital Estimates . . . . . . . . . . . . . . 38

6.2 Other Alternative Cost of Capital Estimates . . . . . . . . . . . . . . 40

6.3 Alternative Diversification Estimates . . . . . . . . . . . . . . 41

$\begin{array}{lll}7 & \text { Conclusion } & 43\end{array}$

Appendix A AQ Related Studies $\quad 45$

$\begin{array}{ll}\text { Appendix B Proofs } & 50\end{array}$

Appendix C Earnings Quality Models $\quad 52$

Appendix D Implied Cost of Capital Models $\quad 54$

$\begin{array}{ll}\text { Bibliography } & 56\end{array}$ 


\section{List of Tables}

Table 1 Variable Descriptive Statistics for the Pooled Sample . . . . . . . 66

Table 2 Time-series Means of Bivariate Correlations . . . . . . . . . . . . 68

Table 3 Independent Sort Performance of $D D$ and $R^{2} \ldots \ldots \ldots$

Table 4 Independent Sort Performance of $|A A|$ and $R^{2} \ldots \ldots 71$

Table 5 Fama-MacBeth Regressions of Implied Cost of Capital on Accruals Quality Metrics . . . . . . . . . . . . 73

Table 6 The Influence of Diversification on the Pricing of Accruals Quality 75

Table 7 Robustness Test - De-biased Implied Cost of Capital Estimates . . 78

Table 8 Robustness Test - Alternative Implied Cost of Capital Estimates . 80

Table 9 Robustness Test - Alternative Definitions for Diversification . . . . 81 


\section{CHAPter 1}

\section{INTRODUCTION}

A fundamental question in accounting research is whether accounting information risk (or information quality) is priced in the capital market. A large literature has theoretically and empirically shown a link between information risk and cost of capital (e.g., Easley and O'Hara, 2004; Francis et al., 2005). ${ }^{1}$ Recently, however, this link between information risk and cost of capital has been contested by a growing number of studies (e.g., Hughes, Liu, and Liu, 2007; Core, Guay, and Verdi, 2008; Caskey, Hughes, and Liu, 2012). The latter studies show that idiosyncratic information risk can be diversified away in the capital market and that no cross-sectional association exists between idiosyncratic information risk and cost of capital. Because accounting information is primarily idiosyncratic in nature, these studies suggest that the link between accounting information risk and cost of capital does not exist in a well-diversified market. ${ }^{2}$ Therefore, it is still unclear whether accounting information risk is priced in the capital market.

This dissertation sheds light on this debate by showing that accounting information risk is priced even if it is entirely idiosyncratic. My hypotheses are model-driven. My

\footnotetext{
${ }^{1}$ Information risk in these studies is defined as "the likelihood that firm-specific information that is pertinent to investor pricing decisions is of poor quality" (Francis et al., 2005). It is defined in the same way in this dissertation.

${ }^{2}$ Several recent studies have shown that information risk has a strong association with idiosyncratic volatility, suggesting that a considerable amount of accounting information is idiosyncratic (e.g., Rajgopal and Venkatachalam, 2011; Chen, Huang, and Jha, 2012).
} 
initial hypothesis derives from the fact that most investors do not hold well-diversified portfolios. In fact, many studies point out that investors are constrained from holding well-diversified portfolios (e.g., Levy, 1978; Merton, 1987; Fama and French, 2007). In this case, Merton (1987), among others, predicts a positive relation between idiosyncratic risk and stock returns. Moreover, his model implies that as investor diversification increases, the positive relation between idiosyncratic risk and stock returns is mitigated.

My further hypotheses are built upon an asset-pricing model derived in Epstein and Schneider (2008). In their model, Epstein and Schneider (2008) distinguish between ambiguous and unambiguous information. Knight (1921) illustrates the concept of ambiguity with an example of two people drawing from an urn containing four balls of two colors: "One man knows that there are red and black balls, but is ignorant of the number of each; another knows that the numbers are three of the former to one of the latter." Ambiguous information refers to the former case when the information can be interpreted under multiple probability distributions. ${ }^{3}$ In contrast, unambiguous (but uncertain) information refers to the latter case when information is interpreted under a unique prior distribution. ${ }^{4}$ Epstein and Schneider (2008) demonstrate that ambiguous information risk cannot be fully diversified away even by holding a well-diversified portfolio. ${ }^{5}$

In this dissertation, I argue that the portion of information risk due to discretionary accruals choices gives rise to ambiguity. ${ }^{6}$ As summarized in Healy and Wahlen (1999), many accounting studies find that managers have both opportunism and signaling motives when making accruals choices. On the one hand, in applying their discretion, managers may be opportunistic and choose reporting methods and estimates for accruals

\footnotetext{
${ }^{3}$ The probability of drawing a red ball can be $25 \%$ when there are one red ball and three black balls, or $50 \%$ when there are two red balls and two black balls, or $75 \%$ when there are three red balls and one black ball.

${ }^{4}$ The probability of drawing a red ball is $75 \%$.

${ }^{5}$ Employing an alternative measure of ambiguity that is derived form a decision-making model called expected utility with random probabilities, Izhakian (2012) also proves that ambiguity cannot be fully diversified away by holding a large portfolio.

${ }^{6}$ In fact, the implications of the Epstein-Schneider model apply to all management disclosures broadly. In this dissertation, I focus on the specific context in which managers are making accrual choices.
} 
to maximize their own interests (i.e., opportunism motive). On the other hand, managers may use their knowledge about the business to select reporting methods and estimates to signal their private information to investors (i.e., signaling motive). ${ }^{7}$ Because investors do not know which motive applies (opportunism vs. signaling), discretionary accruals choices give rise to ambiguity. In other words, the distribution of discretionary accruals conditional on an opportunism motive is different from the distribution conditional on a signaling motive. Investors find discretionary accruals ambiguous because they do not know which motive applies and are facing multiple probability distributions. Therefore, as implied by Epstein and Schneider (2008), discretionary accruals quality cannot be diversified away. Conversely, because managers have little discretion with respect to innate information, innate accruals quality is less ambiguous than discretionary information, and thus innate accruals quality is more likely to be diversified away. ${ }^{8}$

I first examine empirically the extent to which accounting information risk, measured by accruals quality, is priced as diversification changes in an under-diversified market. In particular, I investigate the relation between the firm's cost of capital and accounting information risk, as the extent of diversification varies. Based on Merton (1987), I hypothesize that the pricing of accruals quality decreases as diversification increases. The extent of diversification is gauged by a measure developed in Bushee and Goodman (2010). In particular, using institutional investors holding information, I estimate the extent to which institutional investors' portfolio returns can be explained by market returns, indicating how closely the institutional investors' holdings resemble the market portfolio. A high explanatory power of the relation between institutional investor portfolio returns

\footnotetext{
${ }^{7}$ An example of the dual motives in accruals choices can be illustrated by the valuation allowance for deferred tax assets. While Miller and Skinner (1998) find that this allowance reflects managers' expected future taxable income (i.e., signalling motive), Schrand and Wong (2003) document evidence of earnings management through manipulating this allowance (i.e., opportunism motive).

${ }^{8}$ It is possible that innate information is ambiguous under certain circumstances. For example, it takes time for investors to learn about a newly listed firm especially when the firm has few peers on the market. Thus, innate and discretionary information can both be ambiguous from this aspect. However, discretionary information is still more ambiguous than innate information.
} 
and the market portfolio returns speaks to a high extent of diversification.

I further break down accruals quality into innate and discretionary components. Unlike discretionary accruals which are ambiguous, innate accruals are primarily unambiguous if risky. Therefore, based on the Epstein and Schneider (2008) model, I hypothesize that while the pricing of accruals quality decreases with diversification for innate accruals, diversification is less salient in the pricing of discretionary accruals quality. The empirical results support my model-based hypotheses. I first show a strong relation between accruals quality metrics and firms' cost of capital. Furthermore, after decomposing accruals quality into two components, I find that diversification has a much stronger impact on the pricing of innate accruals quality than that on the pricing of discretionary accruals quality. Although diversification significantly reduces the cost of capital effect of innate accruals quality, it has little impact on the cost of capital effect of discretionary accruals quality. In particular, as one moves from the bottom to the top diversification decile, approximately $80 \%$ of the cost of capital effect of the innate accruals quality is diversified away, but little change is observed for the cost of capital effect of the discretionary accruals quality. These results hold for a number of accruals quality measures and are robust to conventional risk factors, analyst forecast bias, and industry effects. Moreover, the inferences remain unchanged when subjected to a battery of sensitivity tests. Overall, these findings suggest that accounting information risk due to accruals choices cannot be diversified away, as predicted by the Epstein-Schneider ambiguity model.

The next chapter discusses related literature. Chapter 3 presents the Epstein-Schneider model and hypotheses development. Chapter 4 describes the empirical research design, and Chapter 5 presents the data and empirical results. Robustness tests are presented in Chapter 6, and Chapter 7 concludes. 


\section{Chapter 2}

\section{LITERATURE REVIEW}

In this chapter, I briefly discuss two literatures that are related to subsequent chapters of this dissertation. In section 2.1, I discuss analytical and empirical studies examining the relationship between information risk and cost of capital. In section 2.2, I discuss research related to ambiguity and its application in capital markets.

\subsection{Information Risk and Cost of Capital}

\subsubsection{Analytic Work}

This dissertation is closely related to the debate on whether information risk or information quality is priced in capital markets. As pointed out by Beyer et al. (2010), the theoretical underpinning of this debate critically depends on whether information risk is diversifiable.

In their seminal paper, Easley and O'Hara (2004) provide a link between information risk and cost of capital. In particular, extending Grossman and Stiglitz's (1980) rational expectation model, Easley and O'Hara (2004) demonstrate that more private information increases the risk faced by uninformed investors. Because uninformed investors are not able to adjust their portfolio weights in the same way as informed investors, unin- 
formed investors ask for a higher cost of capital to compensate for this risk. Therefore, information risk is priced.

In contrast, Hughes, Liu, and Liu (2007) extend Easley and O'Hara's (2004) model to a large economy in which the full extent of diversification is present. They conclude that information risk is either diversifiable or subsumed by existing risk factors. Therefore, in a large economy, information risk associated with idiosyncratic factors is fully diversifiable and should not affect the cost of capital in a systematic manner. ${ }^{1}$

Similarly, Yee (2006) demonstrates that only the systematic (or undiversified) component of accounting information risk contributes to the equity risk premium and the idiosyncratic part is not reflected in the equity risk premium.

In addition, a few studies analyze whether information risk or information quality is priced although their major focus is not on the diversifiability of the risk. For example, Lambert, Leuz, and Verrecchia $(2007,2012)$ show that the information effect developed in Easley and O'Hara (2004) can be eliminated by perfect competition among investors. In particular, information risk has no effect when the number of traders becomes large. However, the mechanism in these papers is conceptually different from diversification. ${ }^{2}$ Christensen, Rosa, and Feltham (2010) examine this issue from a different aspect. They investigate how information affects the timing of resolution of uncertainty. They demonstrate that information quality affects the timing of resolution of uncertainty but does not affect the firm's overall cost of capital, as long as real effects are ignored.

\footnotetext{
${ }^{1}$ They state that "The analysis in this paper demonstrates that the pricing effect characterized by Easley and O'Hara (2004) proposition 2 can be diversified away when the economy is large (emphasis added) ... Many empirical papers in accounting cite Easley and O'Hara's results as an explanation for an asymmetric information risk premium without recognizing the role played by under diversification due to the restriction to a finite set of assets."

${ }^{2}$ In my empirical tests, I separate this effect from diversification. Specifically, I examine the effect of diversification after controlling for the degree of competition among investors.
} 


\subsubsection{Empirical Evidence}

Much prior empirical research examines whether accruals quality, or more broadly, information risk, is a priced factor that impacts the cost of capital. In particular, in their influential paper, Francis et al., (2005) (FLOS hereafter) examine the link between accruals quality and the cost of capital. In their paper, the cost of capital is captured by industry-adjusted earnings-price ratios and factor loadings in conventional one-factor and three-factor asset-pricing models. They first show that firms with poor accruals quality have higher realized returns, higher costs of debt, higher betas, and higher $\mathrm{P} / \mathrm{E}$ ratios than firms with good accruals quality. They further estimate a time-series regression of each firm's realized returns on the accruals quality risk factor after controlling for other risk factors such as the market, firm size, and book-to-market, and take an average of the coefficients on the accruals quality risk factor for all time-series regressions. They find that the average of the coefficients is positive and statistically significant. Hence, they argue that accruals quality is a priced factor in the cost of equity capital.

Countering FLOS's argument, Core, Guay, and Verdi (2008) (CGV hereafter) contend that FLOS's time-series regressions of stock returns on the factor returns do not test the hypothesis that accruals quality is a priced factor. They adopt two-pass regression method and conduct cross-sectional regressions (CSR) of stock returns on estimated factor loadings. They find that the CSR coefficients on the accruals quality betas are not statistically significant. They also show that there is no association between accruals quality and future stock returns. They thus argue that there is no evidence that accruals quality is a priced factor.

The influential though conflicting empirical results from FLOS and CGV have spurred a number of subsequent studies. Kim and Qi (2010) argue that the failure of CGV to find an association between accruals quality and stock returns is due to the lack of control for low-priced stocks. They repeat CGV's tests, and find a positive risk premium to accruals quality when low-priced stocks have been controlled. Likewise, Ogneva (2012) 
stresses the importance of controlling for cash flow shocks. She hypothesizes and finds that realized returns are negatively associated with accruals quality after controlling for cash flow shocks. However, Mashruwala and Mashruwala (2011) report a significant premium in realized returns in January, but not in other months. They conclude that this finding is difficult to reconcile with a priced risk interpretation of accruals quality. ${ }^{3}$

The literature also employs measures other than accruals quality to proxy for information risk and tests their cost of capital effect. For example, based on a market microstructure model, Easley and O'Hara (2002) derive a measure of the probability of information-based trading (PIN). They estimate this probability for a large sample of NYSE-listed stocks and find that it has a large and significantly positive effect on assets returns. Moreover, they find that PIN dominates all other variables, including beta, in explaining returns. In contrast, Mohanram and Rajgopal (2009) fail to document any empirical specification in which PIN is positively and statistically associated with ex ante measures of cost of equity capital. Specifically, they find that the average PIN loading for small firms is negative, whereas for large firms it is positive. Moreover, they document that the PIN factor loadings are unrelated to stock returns and that there appears to be no robust relationship between PIN and ex ante measures of the cost of capital. ${ }^{4}$

Furthermore, a number of studies have investigated the cost of capital effect of information risk in an international setting. For example, Francis, Khurana, and Pereira (2005) examine whether disclosure incentives are a mechanism to lower the firm's cost of capital in countries outside the U.S.. Their argue that disclosure policy is an instrument for mitigating information asymmetry, or information risk, and it is especially important in settings where the underlying institutions differ considerably from the U.S. in terms

\footnotetext{
${ }^{3}$ Using the ex ante cost of capital instead of realized returns, Bhattacharya et al. (2012) confirm that there is no January effect. They find the association between accruals quality and their ex ante cost of capital is similar in magnitude in January and non-January months, and the association is always significant.

${ }^{4}$ In another concurrent paper, Duarte and Young (2008) also challenges the pricing of information risk as proxied by PIN. They report that the PIN component related to asymmetric information is not priced, while the PIN component related to illiquidity is priced.
} 
of investor protection and the development of financial markets. Using a sample from 34 countries, they show that higher disclosure levels are associated with a lower cost of capital after controlling for cross-country institutional differences in legal and financial systems.

Although it is still debatable whether information risk is diversifiable, a large literature continues to make inferences based on the findings that information risk, as proxied by accruals quality, is priced. These studies include Bhattacharya et al. (2003), Aboody, Hughes, and Liu (2005), Chen, Shevlin, and Tong (2007), Lui, Markov and Tamayo (2007), Bharath, Sunder, and Sunder (2008), Francis et al. (2008), Krishnan, Srinidhi,

and Su (2008), Ashbaugh-Skaife et al. (2009), Lee and Masulis (2009), Kravet and Shevlin (2010), Bhattacharya et al. (2012), and Callen, Khan, and Lu (2012) (Appendix A lists details of these papers). A better understanding of whether information risk is priced therefore seems critical.

Related to this dissertation, two recent studies document that investor competition has an effect on how information risk affects the cost of capital (Armstrong et al., 2011; Akins, Ng, and Verdi 2012). Specifically, relying on theories primarily derived in Lambert, Leuz, and Verrecchia (2007), these papers hypothesize and find that a lower pricing of information is associated with higher competition among investors. In essence, investor competition is different from the notion of diversification. In the robustness tests, I show that the empirical results in this dissertation are not driven by investor competition.

\subsection{Ambiguity}

This dissertation introduces ambiguity into the analysis of accounting information risk. The issue of ambiguity was first addressed by Knight (1921), who distinguishes between measurable uncertainty or risk, which can be represented by precise probabilities, and unmeasurable uncertainty, which cannot. Precisely, ambiguity refers to the situation when 
an individual may face multiple probability distributions over possible outcomes and the outcomes depend on subjective probability distributions. In contrast, risk refers to the situation when an individual faces a unique probability distribution and the outcomes depend on the objectively known probability distribution. Uncertainty encompasses both risk and ambiguity. ${ }^{5}$

\subsubsection{Subjective Expected Utility Theory}

As a starting point of the literature, I first present Savage's (1954) Subjective Expected Utility (SEU hereafter) theory in this subsection. The $S E U$ theory is still considered today as one of the major achievements in decision theory. ${ }^{6}$ Savage (1954) delivers the classic subjective expected utility representation of preferences. Savage thus ties together the idea of subjective probability advocated by Ramsey and de Finetti with the idea of expected utility derived (with given probabilities) by von Neumann and Morgenstern.

The setup of the Savage $S E U$ model includes a few primitives, i.e., a set $X$ of outcomes, a set $S$ of states, a set $A$ of acts and a preference ordering $\succeq$ over acts. In particular, an outcome $x$ is assumed to specify all that is relevant to one's well-being, insomuch as it may be relevant to one's decision. The set of states, $S$, refers to an exhaustive list of all scenarios that might unfold. Moreover, an event is often used to denote a subset $E \subset S$. The objects of choice are acts $a \in A$, which are defined as functions from states to outcomes. That is,

$$
A=X^{S}=\{a \mid a: S \rightarrow X\}
$$

The preferences relation is denoted by $\succeq$, and $f \succeq g$ means that the decision maker prefers act $f$ to act $g$.

\footnotetext{
${ }^{5}$ Some literature uses the term "uncertainty" to refer to situations of unknown probability distributions and "certainty" to refer to situations of known probability distributions.

${ }^{6}$ Karni and Schmeidler (1991) refer to Savage's (1954) SEU theory as the "first, complete and still unsurpassed axiomatization of decision making under uncertainty."
} 
For example, suppose a person endowed with initial wealth $\omega$ is facing a risk of loss $d$. The state space is $S=\{L, \bar{L}\}$, where $L=\{$ loss $\}$ and $\bar{L}=\{$ noloss $\}$. The person can buy full coverage insurance at a premium $\pi$. Thus, the set of acts $A$ includes the acts "buy the insurance" or "not to buy the insurance". The set of outcomes is $X=\{\omega, \omega-\pi, \omega-d\}$. While the act "buy the insurance" maps both the states $L$ and $\bar{L}$ to the outcome $\omega-\pi$, the act "not to buy the insurance" maps states $L$ and $\bar{L}$ to the outcome $\omega$ and $\omega-d$, respectively. Essentially, probability is not included in the primitives in $S E U$ theory.

Savages theorem can be expressed as follows. Assume $\succeq$ satisfies a number of axioms, then there exists a probability measure $\mu$ on $S$ and a function $u: X \rightarrow \mathbb{R}$ such that for any decision $f$ and $g$

$$
f \succeq g \Leftrightarrow \int_{S} u(f(s)) d \mu(s) \geq \int_{S} u(g(s)) d \mu(s)
$$

In this formula, $\mu$ is interpreted as a subjective probability distribution over the state space. It represents the decision maker's beliefs. $u$ is a utility function over outcomes, and represents the decision maker's taste. Furthermore, $\mu$ is unique and $u$ is uniquely defined up to a positive affine transformation.

Savage's (1954) SEU theory is built on a few "reasonable" restrictions, or axioms, on preferences. Although the construction is widely adopted in economics, empirical researchers have presented many challenges to these axioms. The most controversial one is often referred to as the "Sure Thing Principle". ${ }^{7}$

To illustrate this axiom, let $f, g, f^{\prime}, g^{\prime}$ be decisions and $E$ an event. Assume

$$
f(s)=f^{\prime}(s) \text { and } g(s)=g^{\prime}(s) s \in E
$$

and

$$
f(s)=g(s) \text { and } f^{\prime}(s)=g^{\prime}(s) s \in E^{c}
$$

\footnotetext{
${ }^{7}$ Some researchers use the name "Sure Thing Principle" to denote other axioms. For example, Wakker (1993) points out that in Savage's (1954) original usage the term refers to this axiom in conjunction with two other axioms. But the most common usage identifies the term in the same way as this dissertation.
} 
then, $f \succeq g \Leftrightarrow f^{\prime} \succeq g^{\prime}$.

Basically, the acts $f^{\prime}$ and $g^{\prime}$ and the acts $f$ and $g$ only differ on $E$. However, $f^{\prime}$ and $g^{\prime}$ are equal on $E^{c}$. So are $f$ and $g$. Hence, the axiom says that the preference between two acts, $f^{\prime}$ and $g^{\prime}$, should only depend on the values of $f^{\prime}$ and $g^{\prime}$ when they differ (i.e., when $s \in E)$.

\subsubsection{Decision Making under Ambiguity}

Researchers have found empirical results that violate the "Sure Thing Principle". A famous example is Ellsberg's (1961) paradox. He proposes two thought experiments to illustrate the fact that the "Sure Thing Principle" is not an intuitive principle.

In a so-called two-urn experiment, a subject is choosing between two urns containing 100 balls each in which the color of the balls is either red or black. ${ }^{8}$ In the first urn, namely, Urn I, the subject is aware that there are 50 red balls and 50 black balls. The subject, on the other hand, is not informed of the proportion of red and black balls in Urn II.

When placed in a choice situation, it seems plausible that most subjects prefer a bet that pays when red is drawn from the first urn to a bet that pays when red is drawn from the second urn. Meanwhile, most subjects also prefer a bet that pays when black is drawn from the first urn to a bet that pays when black is drawn from the second urn. Thus, the choice pattern observed creates a difficulty to any decision criterion based on probability. No matter what the decision criterion used, if it is probabilistically sophisticated and satisfies the simple dominance principle, the choice of betting on red in Urn I rather than in Urn II reveals that the subject thinks there are less than 50 red balls in Urn II. The choice of betting on black in Urn I reveals that the subject thinks there are less than 50 black balls in Urn II. These two statements create a contradiction.

\footnotetext{
${ }^{8}$ I alter this example to urns containing four balls in Chapter 1 . The inferences remain the same and are insensitive to the number of ball in the example.
} 
In another experiment, the subject is facing an urn with 90 balls in it. She is aware that there are 30 red balls. The remaining 60 are either blue or yellow, in unknown proportion. Similar to the first experiment, when placed in a choice situation, it seems plausible that most subjects prefer a bet that pays when red is drawn from the urn (Act $f$ ) to a bet that pays when blue is drawn from the urn (Act $g$ ). However, most subjects prefer a bet that pays when blue or yellow is drawn from the urn (Act $g^{\prime}$ ) to a bet that pays when red or yellow is drawn from the urn $\left(\right.$ Act $\left.f^{\prime}\right)$. This is a direct violation of the "Sure Thing Principle". To see this, assume the subject is awarded 100 points when the chosen color is drawn from the urn. $f^{\prime}$ and $g^{\prime}$ are obtained from $f$ and $g$ by changing their common outcome of 0 in case a yellow ball is drawn, to a common outcome of 100 . While the "Sure Thing Principle" dictates that $f \succeq g$ and $f^{\prime} \succeq g^{\prime}$, the experimental results show that $f \succeq g$ and $g^{\prime} \succeq f^{\prime}$.

In sum, the inconsistencies in Ellsberg experiments suggest that, when uninformed of the probability distribution or facing ambiguity, decision makers do not behave in a way compatible with $S E U$ preferences. In other words, one cannot assume $S E U$ preferences when decision makers are facing ambiguity.

While Ellsberg (1961) only considers thought experiments, a large body of experimental studies has found behavior patterns consistent with ambiguity aversion (see Camerer and Weber (1992) and Halevy (2007) for reviews of these studies). For example, Fox and Tversky's (1995) experiments suggest a positive association between ambiguity aversion and comparative ignorance. For example, subjects betting on whether a real estate company's share price would rise or fall tend to exhibit more ambiguity aversion when they are told that economics graduate students and professional analysts are also participating in the experiment. Chow and Sarin (2002) find a similar result in an experiment, showing that individuals prefer known risks to risks that are unknown to all parties in the experiment. Moreover, Sarin and Weber (1993) show that ambiguity aversion exists in markets. This is important because the existence of individuals' ambiguity aversion is 
not necessarily reflected in markets. One implication of Sarin and Weber's (1993) results is that ambiguity aversion potentially impacts how information is priced in the capital market.

\subsubsection{Models of Ambiguity Averse Preferences}

Spurred by experimental results of the type reported in Ellsberg (1961) and other papers, a number of models generalizing Savage's $S E U$ preference have been proposed to model ambiguity averse preferences. Because the literature has not reached a consensus on a model of ambiguity aversion, in this dissertation I concentrate on the two models of preferences which are most commonly used in the literature.

A leading model of ambiguity aversion in prior studies is called Maxmin Expected Utility (MMEU) model . The idea is that, when information is ambiguous, decision makers cannot form precise subjective beliefs from objective probability distributions. However, they have "imprecise" subjective beliefs or priors, which are a set of probability distributions. To deal with this set of priors, Gilboa and Schmeidler (1989) provide an axiomatization of the following criterion. A decision $f$ is preferred to a decision $g$ if and only if

$$
\min _{P \in C} E_{p} u(f) \geq \min _{P \in C} E_{p} u(g)
$$

$C$ represents a set of probability distributions over the set of states $S$ and $u$ is a von Neumann-Morgenstern utility function. The decision maker will make his choice between two decisions by comparing the minimal expected utility that each decision yields.

A key axiom in Gilboa and Schmeidler (1989) is an "ambiguity aversion" axiom. It is a modification of the Anscombe and Aumann (1963) axioms, and is consistent with the intuition behind the usual explanation of the modal behaviour in Ellsberg (1961) two-urn experiment. This axiom states that for any acts $f, g \in A$ and $a \in[0,1]$, we have

$$
f \sim g \Leftrightarrow \alpha f+(1-\alpha) g \succeq f
$$


To illustrate this axiom, refer back to Ellsberg two-urn experiment. Let $f$ be the act that yields 100 if the ball drawn from the unknown urn (Urn II) is red and $g$ the act that yields 100 if the ball drawn from the unknown urn (Urn II) is black. Most people would be indifferent between $f$ and $g$. Consider the decision $0.5 f+0.5 g$. If a red ball is drawn, the subject would get 100 with probability 0.5 and 0 with probability 0.5 . Similarly, this act yields the same outcome in case a black ball is drawn. Therefore, this decision amounts to the same thing as a risky bet, whose probability distribution is known. Mixing of the two "uncertain" acts $f$ and $g$ allows one to come up with a new act which is unambiguous: this amounts to saying that by cleverly combining the two acts, one can hedge (fully in the present case) against the ambiguity. Thus, this act is actually the same as a 50:50 bet, i.e., it is equivalent (in a loose sense) to a bet in the known urn. Hence, the preference $\alpha f+(1-\alpha) g \succeq f$ captures the essence of Ellsberg type behaviour.

Another model that is also often adopted in the literature is called Smooth Ambiguity Aversion (SAA) model, proposed in Klibanoff, Marinacci and Mukerji (2005). In their paper, they suggest to replacing the minimum expected utility by some aggregation of all possible expected utilities. To this end, they need some second-order probability, namely, a probability over the probabilities in $S$. Furthermore, they need to introduce some non-linearity in order to capture a non-neutral attitude to ambiguity (otherwise, a prior over all priors would boil down to a Bayesian model again). Therefore, for any acts $f, g \in A$

$$
f \succeq g \Leftrightarrow \int_{C} h\left(\int_{S} u(f(s)) d P(s)\right) d Q(P) \geq \int_{C} h\left(\int_{S} u(g(s)) d P(s)\right) d Q(P)
$$

where $C$ represents a set of probability distributions over the set of states $S, \mathrm{P}$ is a specific element of $c, P$ is a subjective probability distribution over $C$, and $u$ is a von Neumann-Morgenstern utility function. 
The key feature of this model is that $h$ may not be a linear function. ${ }^{9}$ The concavity of $h$ (i.e., $\left.-\frac{h^{\prime \prime}}{h^{\prime}}\right)$ reflects the degree of ambiguity aversion of the decision maker, which is similar to the Arrow-Pratt coefficient of risk aversion. The decision maker behaves more cautiously when betting on probability distributions than when making bets with known odds. An advantage of this model is that an individual with concave functions $u$ and $h$ can be both risk and ambiguity averse and it is possible to compare ambiguity attitudes for individuals who have the same attitude towards risk (that is the same utility function $u)$.

\subsubsection{Ambiguity and Capital Market}

A large number of studies in economics and finance have utilized the concept of ambiguity to explain a variety of issues in capital markets. For example, it has been well documented that a significant proportion of U.S. households, including those with high income, do not participate in stock markets (e.g., Mankiw and Zeldes, 1991). More recent surveys show that even during the 1990's with the tremendous growth of U.S. stock markets, such limited market participation still existed. Cao, Wang and Zhang (2005) attribute this to the existence of ambiguous averse investors. In particular, they demonstrate that limited participation can arise endogenously in the presence of model uncertainty and heterogeneous ambiguous averse investors. When ambiguity dispersion is large, investors with high ambiguity choose not to participate in the stock market, resulting in limited market participation.

Researchers have also used ambiguity aversion to explain home country bias. Epstein and Miao (2003) analyse a pure-exchange, continuous-time economy with two agents and complete markets. In the economy, agents do not view all consumption processes or security returns as purely risky (probabilistic). Rather, they perceive some as ambiguous in the sense illustrated by the Ellsberg Paradox. They show that investors face

\footnotetext{
${ }^{9}$ In fact, it boils down to Savage's $S E U$ model when $h(x)=x$.
} 
greater ambiguity when pricing foreign securities than domestic so that they prefer to hold domestic securities.

While it has been well accepted in the economics and finance literatures that ambiguity plays a significant role in capital markets, very few studies in accounting have examined the role of ambiguity in an accounting context. Caskey (2007) and Williams (2009) are two exceptions. Prior literature suggests that aggregating information not only adds noise to information but also provides an opportunity for managers to place undue emphasis on summary figures such as earnings (e.g., Marschak and Miyasawa, 1968; Graham, Harvey, and Rajgopal, 2005). However, Caskey (2007) shows that aggregate information may be beneficial to investors because it reduces perceived ambiguity. In particular, whereas Savage investors weakly prefer an aggregate signal only if it is a sufficient statistic for its components, ambiguity-averse investors are willing to trade statistical sufficiency for a reduction in ambiguity. This result suggests that easy-to-interpret summary accounting disclosures can mitigate non-participation in the stock market and reduce capital costs. In addition, ambiguity-averse investors' preference for aggregate information implies that equilibrium prices may fail to impound public information, which provides a potential explanation for both underreaction, such as that evident in postearnings announcement drifts and momentum, and overreaction to accounting accruals.

Williams (2009) empirically examines the role of ambiguity in shaping the responses of stock market participants to firm-specific information releases. Prior theoretical studies predict that investors respond differentially to good versus bad news information releases when confronted with ambiguity (e.g., Epstein and Schneider, 2008; Hansen and Sargent, 2010). Using changes in the VIX index as an empirical proxy to capture changes in ambiguity, Williams (2009) shows that following an increase in the VIX there is a significant asymmetric response to earnings news. ${ }^{10}$ Specifically, he finds that investors weight bad

\footnotetext{
${ }^{10}$ In his paper, the VIX index, constructed by the Chicago Board Options Exchange (CBOE), represents the implied volatility of at-the-money option for the S\&P100 index with a maturity of 1 month.
} 
earnings news more heavily than good earnings news, following an increase in the VIX.

In this dissertation, I show that ambiguity can change the way investors interpret accounting information and in turn affect how accounting information risk is priced in the capital market. My results further highlight the importance of considering ambiguity when studying accounting issues. 


\section{Chapter 3}

\section{Hypotheses Development}

\subsection{The Epstein-Schneider Model}

In this section, I use the model developed in Epstein and Schneider (2008) to illustrate whether and when idiosyncratic information risk can be diversified away. Their model is based on a three-period setting in which there is a representative investor, who prices an asset (asset A) based on her prior information and a noisy signal. The three periods are labeled dates 0,1 , and 2. At date 0 , the investor has an unconditional prior distribution over dividends as follows:

$$
d=\mu+\epsilon^{a}+\epsilon^{i},
$$

where $\mu$ is the mean dividend, $\epsilon^{a}$ is a systematic shock, and $\epsilon^{i}$ is an idiosyncratic shock that only affects asset A. Furthermore, $\epsilon^{a}$ and $\epsilon^{i}$ are independent and normally distributed, with a mean of zero. Likewise, the dividend of other assets in this economy is summarized as $\tilde{d}=\tilde{\mu}+\tilde{\epsilon}^{a}+\tilde{\epsilon^{i}}$. Without loss of generalization, assume that there are $\frac{1}{n}$ shares of asset A outstanding and $\frac{n-1}{n}$ shares of other assets outstanding.

Before dividends are revealed at date 2, the investor updates her belief when news about asset A arrives at date 1. Epstein and Schneider (2008) consider two types of news. One is ambiguous news and the other is unambiguous news. Similarly, I classify news into two types, one is innate information driven by economic fundamentals (Type 
$F)$, and the other discretionary information driven by management choices (Type $M$ ). I argue that discretionary information is ambiguous to investors. In particular, as summarized in Healy and Wahlen (1999), managers, in applying their discretion, may be opportunistic and choose reporting methods and estimates to maximize their own interests, i.e., the opportunism motive. Alternatively, they may use their knowledge about the business to select reporting methods and estimates to provide their private information to investors, i.e., the signaling motive. Because investors do not know which motive applies (opportunism vs. signaling), they have multiple prior beliefs on the precision of the information. Therefore, discretionary information, according to Epstein and Schneider (2008), is ambiguous. Conversely, because managers have little discretion with respect to innate information, innate information is less ambiguous than discretionary information.

Furthermore, I assume that both types of news are only about asset A, i.e., they only contain idiosyncratic information. ${ }^{1}$ Therefore, news helps the investor predict the cash flows of asset A, but it cannot help the investor to predict the cash flows of other assets. News is represented by the following signal:

$$
s_{T}=\epsilon^{i}+\epsilon_{T}^{s},
$$

where $T$ denotes the type of the news. When $T=F$ or the news is innate and driven by economic fundamentals, the variance of the shock $\epsilon_{F}^{s}$ is a constant $\sigma_{F}^{2}$. In contrast, when $T=M$ or the news is discretionary and subject to management choices, because the distribution is uncertain to the investor, the variance of the shock $\epsilon_{M}^{s}$ lies in a range $\left[\underline{\sigma}_{M}^{2}, \bar{\sigma}_{M}^{2}\right]$.

Without loss of generality, I assume that the representative investor does not discount the future and only cares about her consumption at date 2. Stated differently, assume that the discount rate is zero, and that she only cares about maximizing her utility at date 2 . News that arrives at date 1 is either innate $\left(s_{F}\right)$ or discretionary $\left(s_{M}\right)$.

\footnotetext{
${ }^{1}$ To highlight the effect of idiosyncratic information risk, I do not include a systematic component in the signal. Inclusion of a systematic component does not affect the inferences of the results.
} 
Case 1: $s=s_{F}$

When the information is innate and unambiguous, assume that the investor is risk averse. Her utility function is given by $u(c)=-e^{-\rho c}$, where $\rho$ is the coefficient of absolute risk aversion. The expected return or cost of capital of asset $\mathrm{A}$ is ${ }^{2}$ :

$$
E(R)=\rho\left(\sigma_{a}^{2}+\frac{1}{n} \sigma_{i}^{2}\right)
$$

where $\sigma_{a}^{2}$ and $\sigma_{i}^{2}$ are the variance of systematic and idiosyncratic risk, respectively. The results in Eq. 3.3 is consistent with prior studies (e.g., Hughes, Liu, and Liu, 2007). In particular, as $n$ converges to infinity, $\sigma_{i}^{2}$ (the variance of idiosyncratic risk) is eliminated. The expected return or cost of capital only depends on the variance of systematic risk $\sigma_{a}^{2}$. In other words, the idiosyncratic risk is not priced in the capital market if $n$ is large.

Case 2: $s=s_{M}$

In this case, the information is discretionary and ambiguous. To derive a transparent closed-form solution, the investor here is assumed to be risk neutral, i.e., $\rho=0 .^{3}$ The expected return or cost of capital of asset $\mathrm{A}$ is:

$$
E(R)=\frac{\sigma_{i}}{\sqrt{2 \pi \bar{\gamma}^{M}}}\left(\underline{\gamma}^{M}-\bar{\gamma}^{M}\right)
$$

where $\bar{\gamma}^{M}=\frac{\sigma_{i}^{2}}{\sigma_{i}^{2}+\bar{\sigma}_{M}^{2}}, \underline{\gamma}^{M}=\frac{\sigma_{i}^{2}}{\sigma_{i}^{2}+\underline{\sigma}_{M}^{2}}$, and $\bar{\gamma}^{M}<\underline{\gamma}^{M}$. It can be seen from Eq. 3.4 that the expected return or cost of capital is a function of the variance of the idiosyncratic risk $\sigma_{i}^{2}$ and will not be eliminated when $n$ converges to infinity. In other words, idiosyncratic risk is priced even in a well-diversified capital market. Hence, idiosyncratic information that helps resolve the idiosyncratic uncertainty (ambiguity) still matters and cannot be diversified away.

The intuition behind this non-diversification result in this model can be described as follows. When information is unambiguous, "good news" and "bad news" cancel

\footnotetext{
${ }^{2}$ Proofs for results in this section are provided in Appendix B.

${ }^{3}$ Assuming risk aversion will not change inferences. In particular, as illustrated in Epstein and Schneider (2008), when information is ambiguous, idiosyncratic risk cannot be diversified away when the investor is risk averse. However, assuming risk neutrality can better reveal the mean effect caused by ambiguous information.
} 
out as the number of stocks in a portfolio becomes large. However, when information is ambiguous, investors assume the worst case scenario (based on the conditional probability that is most damaging to their interests). If ambiguous information conveys "good news", the worst-case scenario is that the "good news" is unreliable. If ambiguous information conveys "bad news", the worst-case scenario is that the "bad news" is reliable. Therefore, "good news" and "bad news" are of different perceived precisions and cannot cancel out any more. Because "bad news" is interpreted by investors to be more precise than "good news" for all stocks, investors act as if the mean of expected payoff is lower for all stocks. In fact, the mean of the expected portfolio payoff is lower no matter how many stocks are included in the portfolio. ${ }^{5}$

\subsection{Hypotheses Development}

In the Epstein-Schneider model, the market is assumed to be well diversified. However, as noted by early studies such as Merton (1987), for various reasons investors may not be able to or may not choose to hold well-diversified portfolios. Therefore, to form empirically testable hypotheses, I examine the association between the pricing of information risk and the extent of diversification, i.e., $n$ in the model. Based on the results in Case 1 as well as those in prior studies (e.g., Hughes, Liu, and Liu, 2007), my first hypothesis, stated in the alternative form, is as follows:

Hypothesis 1: The pricing of information risk is negatively associated with the extent of diversification.

\footnotetext{
${ }^{4}$ Consistent with this notion, a large literature has found that financial report users tend to have greater reactions to "bad news" than "good news" (Jennings, 1987; Williams, 1996; Skinner and Sloan, 2002; Hutton, Miller, and Skinner, 2003; Anilowski, Feng, and Skinner, 2007).

${ }^{5}$ This does not entirely dismiss the effect of diversification. In fact, if the agent were risk averse, the effect of idiosyncratic risk through risk aversion would decrease as $n$ increases. However, compared with the mean effect illustrated in Eq. 3.4, it would be much weaker. In other words, diversification has a much weaker effect for discretionary information than for innate information.
} 
From the analysis in Case 2, when information is decomposed into innate and discretionary information, the effect of diversification is shown to be much weaker on the pricing of ambiguous discretionary accruals quality by comparison to unambiguous (but risky) innate accruals quality. Hence, my second hypotheses, stated in the alternative form, is as follows:

Hypothesis 2: The association between the extent of diversification and the pricing of discretionary information risk is weaker than between the extent of diversification and the pricing of innate information risk. 


\section{Chapter 4}

\section{Research Design}

\subsection{Measuring Accruals Quality}

The analysis in the previous chapter applies to all management disclosures broadly. In this dissertation, I focus on the specific context in which managers are making accruals choices. Therefore, I choose accruals quality as the proxy for information risk. Following the prior literature, I define accruals quality in two ways. First, I define accruals quality as the time-series standard deviation of residuals in regressions of working capital accruals on past, present, and future cash flows from operations, plus the change in revenues and property, plant, and equipment (Dechow and Dichev, 2002; McNichols, 2002). Throughout this disseration, this measure is denoted as DD. Second, I define accruals quality as the absolute value of abnormal accruals, $|A A|$, following a modified Jones (1991) approach, as detailed in Francis et al. (2005). For both variables, larger values indicate poorer accruals quality. The details of how to construct these two measures are provided in Appendix C.

Furthermore, I decompose the accruals quality measures into innate and discretionary components. Innate accruals quality is designed to capture innate information risk, and discretionary accruals quality is designed to capture discretionary information risk. Fol- 
lowing Francis et al. (2005), I use two approaches. The first approach explicitly separates the innate and discretionary components of accruals quality using annual regressions of accruals quality on the innate factors. The regression model is as follows:

$$
\begin{aligned}
A Q_{j, t}= & \lambda_{0, t}+\lambda_{1, t} \operatorname{Ln}\left(\text { Asset }_{j, t}\right)+\lambda_{2, t} \sigma(\text { CFO })_{j, t}+\lambda_{3, t} \sigma\left({\text { Sales })_{j, t}}+\lambda_{4, t} \operatorname{Ln}\left(\text { OperCycle }_{j, t}\right)\right. \\
& +\lambda_{5, t} \text { NegEarn }_{j, t}+\lambda_{6, t} \text { IntIntensity }_{j, t}+\lambda_{7, t} \text { CapIntensity }_{j, t}+\mu_{j, t},
\end{aligned}
$$

where $A Q_{j, t}$ is the respective accruals quality metric for firm $j$ in year $t(D D,|A A|)$, Assets $_{j, t}$ is firm $j$ 's total assets, $\sigma(C F O)_{j, t}$ is the standard deviation of firm $j$ 's cash flow from operations scaled by total assets, $\sigma(\text { Sales })_{j, t}$ is the standard deviation of firm $j$ 's sales scaled by total assets, OperCycle $e_{j, t}$ is the length of firm $j$ 's operating cycle measured as the sum of days accounts receivable and days inventory, $N e g E_{a r n} n_{j, t}$ is the proportion of years (over the estimation period) for which firm $j$ reported negative net income before extraordinary items, IntIntensity $y_{j, t}$ is firm $j$ 's average research and development expense plus advertising expense divided by sales, and CapIntensity $y_{j, t}$ is firm $j$ 's average net PPE scaled by total assets. The predicted value from the regression yields an estimate of the innate portion of firm $j$ 's accrual quality in year $t$, and the prediction error is the estimate of the discretionary component of firm $j$ 's accruals quality in year $t$.

The second approach controls for innate factors affecting accruals quality by including them as independent variables in the costs of capital regression. In these augmented regressions, the coefficient on AQ captures the cost of capital effect of the portion of accruals quality that is incremental to the effect captured by the innate factors. This coefficient is interpreted as a measure of the cost of capital effect of discretionary accruals quality.

\subsection{Measuring the Implied Cost of Capital}

In this dissertation, I employ four accounting based valuation models to estimate the ex ante rate of return implied in contemporaneous stock price and analyst forecast data 
(Claus and Thomas, 2001; Gebhardt, Lee, and Swaminathan, 2001; Easton, 2004; Ohlson and Juettner-Nauroth, 2005). ${ }^{1}$ All four models are derived from the discounted dividend valuation model but exploit accounting relations (e.g., the clean surplus relation) to obtain an equivalent valuation equation based on residual income or abnormal earnings. Market price and analyst forecasts are substituted into the valuation equation to obtain the cost of capital as the discount rate that equates current stock price and the sequence of expected future residual incomes or abnormal earnings. The individual models differ with regards to the use of analyst forecast data, the assumptions of short-term and longterm growth, the explicit forecasting horizon, and the incorporation of industry effects. These models are commonly used in the literature and explicitly separate cash flow effects from cost of capital effects. Details of these models are summarized in Appendix D.

In this dissertation, the estimates from these four models are labeled as $C O C_{C T}$, $C O C_{G L S}, C O C_{P E G}$, and $C O C_{O J}$, respectively. As there is little consensus in the literature regarding which of the models works best (e.g., Botosan, Plumlee, and Wen, 2011), I use the mean of these four proxies $\left(C O C_{A V G}\right)$ as my primary dependent variable. Averaging should reduce idiosyncratic measurement error across the models. In the robustness check, I also repeat my main test using each of these estimates separately.

\subsection{Measuring the Extent of Diversification}

Prior studies suggest that investors may not be able to or may choose not to hold welldiversified portfolios for various reasons. Many studies document that most individual investors invest in a limited number of stocks. For instance, Goetzmann and Kumar (2004) show that, based on a sample of more than 62,000 household investors in the period 1991 to 1996, over $25 \%$ of the investor portfolios contain only one stock, over half contained no more than three stocks, and less than $10 \%$ contained more than 10 stocks.

\footnotetext{
${ }^{1}$ In the robustness tests, realized future returns are employed, and the results are qualitatively similar.
} 
Furthermore, institutional investors often deviate from investing in the market portfolio. Studies show that some institutional investors adopt specific investment strategies such as value or growth strategies (e.g., Abarbanell et al., 2003; Bushee, 2001). In addition, some institutional investors choose to hold large blocks in certain firms and take an active role in governance (e.g., Smith, 1996). If investors deviate from the market portfolio, prior studies suggest that idiosyncratic risk can be priced (e.g., Levy, 1978; Merton, 1987; Fama and French, 2007). Hence, this evidence raises the possibility that the capital market in reality is not as well diversified as assumed in theory.

While it is widely suggested that capital markets are under-diversified, little guidance has been offered in the prior literature on how to gauge the extent of diversification. One exception is Bushee and Goodman (2010). They develop a diversification measure based on the information of a firm's institutional investors. The basic idea is that if an investor holds a well-diversified portfolio, the portfolio return should be sensitive to that of the market portfolio. The diversification measure in this dissertation is built upon this idea. Specifically, I first calculate the return for each individual institution's portfolio in each month based on the ownership disclosed on the preceding calendar quarter filing reported on Thomson Reuters Spectrum (e.g., portfolio weights on March 31 are used to calculate portfolio returns for April, May, and June). Following Bushee and Goodman (2010), I adjust for delisting by assuming that when a portfolio firm delists in the middle of a quarter, the institution re-invests the funds into the CRSP value-weighted index for the remainder of the quarter. The following time-series regression is estimated for each institution in a five-year rolling window:

$$
R_{k, t}-r_{f}=\alpha_{k, t}+\beta_{k, t}\left(R_{m t}-r_{f}\right)+\epsilon_{k, t}
$$

where $R_{k, t}$ is the return for institution $\mathrm{k}$ in month $\mathrm{t}, R_{m t}$ is the market return in month $\mathrm{t}$, and $r_{f}$ the risk free rate. For each institution in month t, this time-series regression is 
estimated using monthly returns in the previous five years, i.e., $\mathrm{t}-60$ to $\mathrm{t}-1 .^{2}$ I further require at least 30 observations in each regression. Therefore, $R^{2}$ from equation (4.2) is used to measure the extent of diversification for institution $k$ in month $\mathrm{t}$.

To obtain a firm level diversification measure, for each firm-quarter I calculate the average $R^{2}$ of all institutions weighted by their ownership of the firm's shares. The average institutional investor is assumed to be the representative of the marginal investors. ${ }^{3}$ This assumption is based on the findings that (1) institutional investors are expected to have bigger impacts on the stock price due to their larger size and sophistication (Hand, 1990), and (2) higher institutional ownership is associated with a more sophisticated marginal investor (Jiambalvo et al., 2002; Piotroski and Roulestone, 2004) and higher efficiency of stock prices (Ali, Hwang, and Trombley, 2003; Collins, Gong, and Hribar, 2003). This procedure results in a firm-quarter diversification measure $R_{i, q}^{2}$ for firm i in quarter q. It is further transformed into a firm-year measure in order to merge with cost of capital and other annual data.

\footnotetext{
${ }^{2}$ Bushee and Goodman (2010) estimate this regression using the full sample period. In the robustness tests, I use the full period and find that the inferences remain unchanged.

${ }^{3}$ Following Bushee and Goodman (2010), I only consider institutional investors in constructing this measure. In other words, the $R^{2}$ I obtain here is the weighted average across institutional investors. However, the inferences remain unchanged if I account for individual investors by assuming they are fully under diversified, i.e., $R^{2}=0$.
} 


\section{Chapter 5}

\section{EMPIRICAL RESULTS}

\subsection{Sample and Descriptive Statistics}

I begin with all non-financial firms from the intersection of COMPUSTAT, CRSP, IBES

and Thomson Reuters Spectrum. Because the institutional ownership information in Thomson Reuters Spectrum is only available starting in 1980, and I require at least 30 months of this information to estimate the extent of diversification, my sample is restricted to the 1982 to 2010 period. Following Gebhardt et al. (2001) and Claus and Thomas (2001), implied cost of capital estimates are imputed as of July 1 each year. The sample size is further reduced after requiring each observation to have one-year-ahead and two-year-ahead non-negative earnings forecasts, a long-term growth forecast, and a contemporaneous share price. To align accruals quality measures with the implied cost of capital, I require the fiscal-year end to be at least four months before June in order to assure that financial data are publicly available and reflected in the market price at the time of my computations. In addition, quarterly data are averaged over the four quarters' estimates that precede the end of June in each year.

Table 1 reports summary descriptive statistics for the pooled sample. Because inclusion of different accruals quality metrics leads to different sample sizes, all variables 
are reported based on the sample size before requiring the availability of accruals quality metrics. Thus, there are 47,854 firm-year observations in total. To avoid giving extreme observations heavy weight in the return regressions and potential data recording errors, the smallest and largest $1 \%$ of the observations in each year for all variables are set equal to the next smallest or next largest values.

First, I list five implied cost of capital estimates in Panel A of Table 1. COC $A V G$ is the average of all the above four estimates used in the prior literature, which is the main proxy for cost of capital in this dissertation. The mean of $C O C_{A V G}$ is $11.65 \%$, and the median is $10.90 \%$. Second, six accruals quality measures are presented in Panel B. While calculating $|A A|$ needs the information in the past and current fiscal year, calculating $D D$ needs information for the past five years. Thus, $|A A|$ is available for more firmyear observations. Separating accruals quality into innate and discretionary components further reduces the sample size. The mean of $D D$ is $3.84 \%$, and the mean of $|A A|$ is $5.82 \%$. The proxy for diversification, $R^{2}$, is reported in Panel B. The mean (median) value of $R^{2}$ is $88 \%(90 \%)$, meaning that the market index explains around $90 \%$ of the return earned by the average institutional investor.

The statistics for control variables are also reported in Panel C. BET A is the portfolio beta as constructed in Fama and French (1992). I use the previous 24 to 60 months of monthly returns (as available) to estimate firm betas by the market model. Stocks are assigned to $10 \times 10$ portfolios on the basis of size and $\beta$. I then compute the equal-weighted portfolio returns. For each size- $\beta$ portfolio, I run the full-period time-series regression of the portfolio return on the current and prior month's value-weighted market returns. The portfolio $\beta$ is estimated as the sum of the slopes of these two market returns, and the sum is meant to adjust for the effects of non-synchronous trading (Dimson, 1979). The mean (median) of BETA is 1.26 (1.24). ME is the market value of equity (ME), which is the product of monthly closing price and the number of shares outstanding. Following Fama and French (1992), I construct book-to-market equity ratio $(B E / M E)$ 
as the fiscal year-end book value of common equity divided by the calendar-year-end market value of equity. The mean and median values of $\operatorname{Ln}(M E)$ and $\operatorname{Ln}(B E / M E)$ are very close, indicating that the skewness issue has been well taken care of by taking a natural logarithm. Lev is defined as the ratio of long-term debt to total assets with a mean (median) of $22 \%(22 \%)$, and $M M T$, which captures price momentum, is the logarithm of one plus the compounded returns over the previous 12 months with a mean of $9 \%$ and a median of $10 \%$. FBI $A S$ is the one-year-ahead forecast error (forecast minus actual value) deflated by lagged price. The mean (median) value of FBIAS is $0.89 \%$ $(0.14 \%)$. The positive mean suggests that analyst forecasts tend to be optimistic about the future earnings. $M M T$ and FBIAS are utilized to control for potential bias in implied cost of capital estimates caused by the optimism in analysts' forecasts.

Table 2 presents the time-series means of bilateral correlations. Two observations are worth mentioning. First, the Pearson (Spearman) correlation between diversification $\left(R^{2}\right)$ and firm size $(\operatorname{Ln}(M E))$ is $16 \%(10 \%)$. Untabulated results show that $R^{2}$ is only moderately correlated with other firm characteristics. ${ }^{1}$ It indicates that $R^{2}$ is not likely to be driven by firm characteristics. Second, FBIAS is positively correlated with $C O C_{A V G}$. The Pearson (Spearman) correlation is $15 \%(19 \%)$, indicating that analyst forecast optimism can bias upward the implied cost of capital estimate as suggested by prior studies (e.g., Claus and Thomas, 2001; Easton and Monahan, 2005). Therefore, the correlation highlights the need for controlling for analyst forecast errors in the analysis.

\subsection{Portfolio Analysis}

I first conduct a portfolio analysis to test how diversification influences the relation between accruals quality and cost of capital. All firm-years are sorted into quintiles by their most recently available accruals quality values and by their diversification measure

\footnotetext{
${ }^{1}$ For example, the highest correlation among them is the one between $R^{2}$ and the number of institutional investors. The Pearson (Spearman) correlation is 13\% (10\%).
} 
independently. Portfolio 1 (Portfolio 5) contains firms having the best (worst) accruals quality. For each of the twenty-five intersections of the two groups, the value-weighted cost of capital are computed for each year, and Tables 3 and 4 show the results. Accruals quality is proxied by $D D$ and $|A A|$ in Tables 3 and 4 respectively. The extent of diversification is proxied by $R^{2}$. Panel A reports the risk premium, i.e., $C O C_{A V G}-r_{f}$, and Panel B reports the stock returns adjusted for the Fama-French three factors, i.e., the Fama-French Alpha.

Because the results are similar across different accruals quality and abnormal return metrics, I present results for $D D$ and the risk premium. As illustrated in Panel A of Table 3, the bottom row shows the difference in cost of capital between top (best) and bottom (worst) $D D$ quintiles, i.e., the hedge return. The hedge returns are significantly positive in all quintiles, indicating that investors charge a higher cost of capital to compensate for low accruals quality. Moreover, as one moves from Column 1 (the lowest extent of diversification) to Column 5 (the highest extent of diversification), the hedge return shrinks from $1.33 \%$ to $0.64 \%$. Untabulated results show that the difference is significant at the $1 \%$ level. These two observations together are consistent with the first hypothesis. Specifically, the negative association between hedge returns and the extent of diversification supports the notion that accounting information proxied by accrual quality is associated with idiosyncratic risk that can be diversified (e.g., Hughes, Liu, and Liu, 2007). In addition, the positive hedge returns suggest that although accounting information risk can be diversified away, it is still priced because market participants are under-diversified as in Merton (1987).

The evidence is also consistent with the second hypothesis. In particular, the cost of capital difference between the top and bottom $D D$ quintiles remains significantly positive even in the highest diversification quintile. Therefore, accounting information risk does not appear to be fully diversified away. In fact, the model in Section 3 predicts that although the innate information risk can be fully diversified away, the discretionary 
component cannot. This issue will be further investigated in the following multivariate analysis.

\subsection{Multivariate Analysis}

\subsubsection{The Association Between Accruals Quality and Cost of Capital}

I begin the multivariate analysis by exploring the association between accruals quality and cost of capital. I estimate the following regression model:

$$
\begin{aligned}
\operatorname{COC}_{i, t}= & \alpha_{t}+\gamma_{1, t} B E T A_{i, t}+\gamma_{2, t} \operatorname{Ln}\left(M E_{i, t-1}\right)+\gamma_{3, t} \operatorname{Ln}\left(B E_{i, t-1} / M E_{i, t-1}\right)+\gamma_{4, t} \operatorname{Lev}_{i, t-1} \\
& +\gamma_{5, t} M M T_{i, t-1}+\gamma_{6, t} F B I A S_{i, t+1}+\beta_{t} A Q_{i, t-1}+\sum \text { IndustryControl }+\epsilon_{i, t}
\end{aligned}
$$

where the dependent variable is $C O C_{A V G}$, which is the mean of four implied cost of capital estimates imputed from commonly used accounting valuation models. I use both $D D$ and $|A A|$ as accruals quality proxies, which are estimated based on a modified Dechow and Dichev (2002) model and a modified Jones (1991) model, respectively. These two metrics are further decomposed into innate and discretionary components by two approaches as detailed in Section 4.1. My main interest is the coefficient of AQ (i.e., $\beta$ ), which is predicted to be positive.

Following the prior literature, I include a set of control variables that may affect the cost of capital. First, I control for the portfolio beta (BETA) and expect that $\gamma_{1}>0$. Fama and French (1992) find that stock returns are negatively correlated with firm size and are positively correlated with book-to-market equity. Firm size $(M V)$ is measured as the logarithm of the market value of common equity. Book-to-market equity $(B E / M E)$ is constructed as the logarithm of the ratio of the fiscal-year-end book value of common equity divided by the calendar-year-end market value of equity. I expect that $\gamma_{2}<0$ and 
$\gamma_{3}>0$. Modigliani and Miller (1958) argue that the cost of equity should increase as leverage increases. I include a leverage ratio $($ Lev $)$ and expect $\gamma_{4}>0$

In addition, I note that the implied cost of capital estimates can be affected by forecast bias (Easton and Sommers, 2007). Two variables are included to control for this bias. First, I include price momentum $(M M T)$ to mitigate the bias driven by analysts' sluggishness with respect to information in past stock returns (Guay, Kothari, and Shu, 2011). $M M T$ is defined as the logarithm of one plus the compounded returns over the previous 12 months. I expect that $\gamma_{5}<0$. Second, following Hail and Leuz $(2006,2009)$, I control for analyst forecast errors. $F B I A S$ is the one-year-ahead forecast error (forecast minus actual value) deflated by lagged price. $^{2}$ I expect that $\gamma_{6}>0$.

Finally, I control for industry-fixed effects in my regression model. Cost of capital is shown to vary substantially across industries (Fama and French, 1997). Therefore, I use the Fama and French (1997) 48-industry classification to construct industry indicators.

I use Fama and MacBeth (1973) regressions to control the cross-correlation in residuals. ${ }^{3}$ The results are reported in Table 5. First, columns 1 and 4 examine whether the total AQ is priced. The coefficient on $D D(|A A|)$ is $0.13(0.04)$ and significant at the $1 \%$ level. These results are consistent with prior studies that document an association between accruals quality and implied cost of capital (e.g., Bhattacharya et al., 2012; Callen, Khan, and Lu, 2012). It indicates that investors charge a high cost of capital when accruals quality is low. In columns $2,3,5$ and $6, D D$ and $|A A|$ are separated into innate and discretionary components using two approaches, respectively. The first approach explicitly separates these two components by regressing total AQ on innate factors, and the second approach instead controls innate factors in the regression. It appears that the

\footnotetext{
${ }^{2}$ McInnis (2010) finds that the optimism in analyst forecasts yields implied cost of capital estimates that are systematically too high for firms with volatile earning. To ensure the results are not driven by earnings volatility, I further control for earnings smoothness as defined in McInnies (2010). Untabulated results show that the inferences remain unchanged after controlling for earnings smoothness.

${ }^{3}$ Fama and MacBeth (1973) regressions also allow coefficients to vary over time. The references remain the same when data is pooled and standard errors are clustered by year and firm.
} 
coefficients of both innate and discretionary AQ are significantly positive. For example, in column 2, the coefficients on innate (discretionary) AQ is $0.26(0.04)$ and is significant at the $1 \%$ level. In column 3, the coefficient on discretionary AQ is 0.05 and is significant at the 1\% level. This is consistent with the findings in Francis et al. (2005), who also find lower coefficients on discretionary AQ than those on innate AQ. The results are similar when $\mathrm{AQ}$ is proxied by $|A A|$.

Regarding control variables, I find that the signs of the coefficients are all consistent with expectations. Cost of capital is positively associated with beta, book to market ratio, leverage, and analysts' forecast bias, and negatively associated with firm size and price momentum.

\subsubsection{The Influence of Diversification on the Pricing of Accruals Quality}

Next, I analyze whether the association between accruals quality and cost of capital documented in Table 5 can be mitigated by diversification. To make the exposition easier, I rank $R^{2}$ into deciles every year and then scale the decile rank so that it ranges from 0 to $1 .^{4}$ The decile rank of diversification is denoted as $D\left(R^{2}\right)$ and interacts with the accruals quality metrics. Thus, the regression model augmented with diversification is as follows:

$$
\begin{aligned}
\operatorname{COC}_{i, t}= & \alpha_{t}+\gamma_{1, t} B E T A_{i, t}+\gamma_{2, t} \operatorname{Ln}\left(M E_{i, t-1}\right)+\gamma_{3, t} \operatorname{Ln}\left(B E_{i, t-1} / M E_{i, t-1}\right)+\gamma_{3, t} L_{e v_{i, t-1}} \\
& +\gamma_{4, t} M M T_{i, t-1}+\gamma_{5, t} F B I A S_{i, t+1}+\delta_{t} D\left(R^{2}\right) \\
& +\sum_{M=\text { Total|(Innate\&Disc) }} A Q_{M}\left(\beta_{M}+\theta_{M} D\left(R^{2}\right)\right)+\sum \text { IndustryControl }+\epsilon_{i, t} .
\end{aligned}
$$

\footnotetext{
${ }^{4}$ The results are robust to the quintile and percentile ranks.
} 
My main interest is the coefficients of the interaction terms between AQ metrics and $D\left(R^{2}\right)$, i.e, $\theta_{M}$. $\theta_{M} / \beta_{M}$ reveals how much the information risk can be diversified away as one moves from the bottom diversification decile to the top diversification decile.

The results are reported in Table 6. Because they are very similar across two accrual quality measures ( $D D$ and $|A A|)$, I use $D D$ for illustration. Columns 1 and 4 present the results for total AQ. For example, in column 1 the coefficient on AQ is 0.18 and is significant at the $1 \%$ level. More importantly, the coefficient on $\mathrm{AQ} \times D\left(R^{2}\right)$ is -0.14 and is significant at the $1 \%$ level. These results suggest that investors charge less for bearing information risk when they are well diversified. Regarding the economic significance of this finding, a comparison between the coefficient on $\mathrm{AQ}$ and that on the interaction term reveals that as one moves from the bottom to the top decile, approximately $78 \%$ $(0.14 / 0.18)$ of information risk is diversified away. This evidence supports Hypothesis 1 and is consistent with the notion that information risk proxied by accruals quality is diversifiable.

Furthermore, in columns 2, 3, 5, and 6, total AQ is separated into two components: innate and discretionary AQ. In column 2, the coefficient on innate (discretionary) AQ is $0.30(0.05)$ and is significant at the $1 \%(5 \%)$ level, meaning that investors charge a higher cost of capital to compensate for both types of information risk. However, the effects of diversification on these two components are distinct. In particular, the coefficient on innate $\mathrm{AQ} \times D\left(R^{2}\right)$ is -0.24 and is significant at the $1 \%$ level. This indicates that as one moves from the bottom to the top decile, approximately $80 \%(0.24 / 0.30)$ of information risk is diversified away. On the other hand, the coefficient on discretionary $\mathrm{AQ} \times D\left(R^{2}\right)$ is -0.02 and is insignificant. In column 3, when discretionary AQ is separated out under the second approach, the coefficient on discretionary $\mathrm{AQ} \times D\left(R^{2}\right)$ is -0.01 and is still insignificant. The insignificant coefficients on discretionary $\mathrm{AQ} \times D\left(R^{2}\right)$ suggest that little of the cost of capital effect of discretionary information risk can be mitigated by diversification. It supports Hypothesis 2 in that diversification has much weaker effects 
on the discretionary information risk than on the innate information risk. Similar results are also observed when accruals quality is proxied by $|A A|$ in columns 5 and 6 .

Overall, the results in Table 6 confirm the findings in the portfolio analysis. First, it demonstrates a strong association between the pricing of innate information risk proxied by accruals quality and diversification. This result is consistent with Hypothesis 1 and indicates that (1) innate information risk is diversifiable, and (2) innate information risk is priced because the market is under-diversified.

Second, the results reveal that although innate information risk (proxied by innate AQ) can be diversified away, discretionary information risk (proxied by discretionary AQ) cannot. They are consistent with the predictions obtained from the model in Section 3 and support Hypothesis 2. This table also highlights the important effects of diversification on the pricing of information risk. 


\section{Chapter 6}

\section{Robustness Checks}

This chapter presents several robustness checks for the main results in Table 6. First, I de-bias the cost of capital estimates using the methodology introduced in two recent studies. Then, I examine whether my findings hold for each estimate from the four implied cost of capital models, for an alternative way to aggregate the four estimates, and for realized returns. Finally, I assess whether my results are sensitive to alternative proxies for diversification.

\subsection{De-biased Cost of Capital Estimates}

A few papers on estimating implied cost of capital have expressed concerns regarding the optimism in analysts' forecasts as a potential source of error in cost of capital estimation (Claus and Thomas, 2001; Easton and Monahan, 2005). Recently, two papers have used comprehensive approaches to adjusting forecasts for predictable forecast errors (Mohanram and Gode, 2013; Larocque, 2013). In particular, Mohanram and Gode (2013) remove predictable errors from analyst forecasts using a model based on Hughes, Liu, and Su (2008) and show a much stronger relationship between the de-biased cost of capital estimates and realized returns. In order to make sure that the main results in this

dissertation are not affected by the optimism in analysts' forecasts, I replicate the main 
tests using the de-biased cost of capital estimates. ${ }^{1}$ First, the following two regressions are estimated for each year:

$$
\begin{aligned}
S U R P_{1}= & \eta_{0, t}+\eta_{1, t} T A_{i, t}+\eta_{2, t} \Delta \text { Sales }_{i, t}+\eta_{3, t} L T G_{i, t}+\eta_{4, t} \Delta P P E_{i, t}+\eta_{5, t} \Delta O L A_{i, t} \\
& +\eta_{6, t} R E T_{i, t-1}+\eta_{7, t} R E V_{i, t-1}+\tau_{i, t} \\
S U R P_{2}= & \delta_{0, t}+\delta_{1, t} T A_{i, t}+\delta_{2, t} \Delta \text { Sales }_{i, t}+\delta_{3, t} L T G_{i, t}+\delta_{4, t} \Delta P P E_{i, t}+\delta_{5, t} \Delta O L A_{i, t} \\
& +\delta_{6, t} R E T_{i, t-1}+\delta_{7, t} R E V_{i, t-1}+\psi_{i, t},
\end{aligned}
$$

where $S U R P_{1}\left(S U R P_{2}\right)$ is the one- (two-) year analyst forecast error scaled by stock price, $T A$ is total accruals, $\triangle$ Sales is sales growth, $L T G$ is the median analyst longterm growth estimate, $\triangle P P E$ is growth in PP\&E, $\triangle O L A$ is growth in other long-term assets, and RET is the annual buy-and-hold returns. A lagged RET is used so that it is known before the forecast is issued. $R E V$ is the difference between consensus analysts' one-year-ahead forecast and the forecast at the start of the year. Untabulated results show that the mean coefficients obtained from these two regressions are similar to those reported in Panel B of Table 6 in Mohanram and Gode (2013).

The coefficients $\eta$ 's and $\delta$ 's estimated at year t are multiplied with realized values in year $t+1$ to predict the forecast errors for earnings at year $t+1$. For example, I use the $\eta$ 's and $\delta$ 's estimated in year 2000 to predict the forecast errors $P S U R P_{1}$ and $P S U R P_{2}$ in year 2001 and get adjusted analyst' forecasts $A E P S_{1}=E P S_{1}+P S U R P_{1} \times$ Price and $A E P S_{2}=E P S_{2}+P S U R P_{2} \times$ Price. The de-biased cost of capital estimates are recomputed using the adjusted analyst' forecasts.

Table 7 reports the Fama-Macbeth regression results based on the mean of de-biased cost of capital estimates. The coefficients on the interaction terms between innate AQ and $D\left(R^{2}\right)$ continue to be significantly negative $(-0.27$ and -0.16 and significant at $1 \%$ level for $D D$ and $|A A|$, respectively), indicating a strong mitigating effect of diversification

\footnotetext{
${ }^{1}$ The inferences remain unchanged when cost of capital estimates are estimated using the method introduced in Larocque (2013).
} 
on the pricing of innate AQ. In contrast, the interaction terms between discretionary AQ and $D\left(R^{2}\right)$ continue to be weak (-0.02 and -0.01 and insignificant for $D D$ and $|A A|$, respectively), indicating a limited effect of diversification on the pricing of discretionary AQ. Hence, the results demonstrate that analyst optimism does not alter the main results.

\subsection{Other Alternative Cost of Capital Estimates}

In Table 8, I report results using implied cost of capital estimates from each of the four models, the first principal component of the four individual estimates ${ }^{2}$, and monthly realized returns as alternative proxies for cost of capital. ${ }^{3}$ For the sake of brevity, only the results of innate and discretionary $\mathrm{AQ}$ proxied by $D D$ are reported but the results of $\mathrm{AQ}$ proxied by $|A A|$ are qualitatively similar. As shown in Table 8, the results for all of these refinements are consistent with those in Table 6 and lead to the same inferences as before. In particular, the coefficients on innate $\mathrm{AQ}$ and discretionary $\mathrm{AQ}$ remain significantly positive across all cost of capital estimates. More importantly, the coefficients on the interaction between innate $\mathrm{AQ}$ and $D\left(R^{2}\right)$ are all significantly positive and the coefficients on interaction between discretionary $\mathrm{AQ}$ and $D\left(R^{2}\right)$ remain insignificant. For example, when cost of capital is proxied by $C O C_{C T}$, while the coefficient on innate $\mathrm{AQ} \times D\left(R^{2}\right)$ is -0.45 and is significant at the $1 \%$ level, the coefficient on innate $\mathrm{AQ} \times D\left(R^{2}\right)$ is -0.06 and is insignificant. Therefore, these results demonstrate that my findings do not depend on the choice of cost of capital estimates or the method of aggregation.

\footnotetext{
${ }^{2}$ Untabulated results show that the first principal component explains $70 \%$ of the total variance.

${ }^{3}$ Realized returns are measured in the same period as the implied cost of capital estimates, i.e., from 1982 to 2010. Following Kim and Qi (2011), I eliminate low-priced stocks in the sample.
} 


\subsection{Alternative Diversification Estimates}

In Table 9, I address the concern that my findings may be driven by the way I measure the extent of diversification. First, my main proxy for diversification $R^{2}$ is obtained from the characteristics of the average institutional investor. A potential endogeneity issue arises when the characteristics of the average institutional investor are not exogenous with respect to firm characteristics. For example, better-diversified investors are more likely to invest in larger firms. Furthermore, two recent studies document that investor competition affects the relation between the information asymmetry and cost of capital (Armstrong et al., 2011; Akins, Ng, and Verdi 2012). In essence, competition is different from the notion of diversification. However, their measures of competition are based on the number of institutional investors and ownership concentration. It is possible that under-diversification is more likely to happen when investor competition is low. Therefore, my previous findings could be simply the manifestation of firm characteristics or investors competition rather than diversification. Hence, I estimate a regression model to remove variations related to a group of firm characteristics and investor competition measures. The model is as follows:

$$
\begin{aligned}
R_{i, t}^{2}= & \mu_{0, t}+\mu_{1, t} B E T A_{i, t}+\mu_{2, t} \operatorname{Ln}\left(M E_{i, t}\right)+\mu_{3, t} \operatorname{Ln}\left(B E_{i, t} / M E_{i, t}\right)+\mu_{4, t} I O_{i, t} \\
& +\mu_{5, t} \operatorname{Ln}\left(1+n_{-} \text {Inst }_{i, t}\right)+\mu_{6, t} \text { HerfInst }+\kappa_{i, t},
\end{aligned}
$$

where BETA, $M E$, and $B E$ are portfolio BETA, market, and book value of equity as defined earlier. $I O$ is the total institutional ownership and $n_{-}$Inst is the number of institutional investors. HerfInst is a Herfindahl index computed as follows:

$$
{\text { Herf } \text { Inst }_{i}}=-1 \times \sum_{j=1}^{N}\left(\frac{\text { Investor }_{i, j}}{\text { Investor } s_{i}}\right)^{2},
$$

where Investor $_{i, j}$ is the number of shares held by institutional investor $j$ in stock $i$. Investor $s_{i}$ is the total shares held by all institutional investors of stock $i$, and $N$ is the total number of institutional investors in stock $i$. The Herfindahl index is multiplied 
by -1 so that a higher value of Herf Inst measures more competition in the trades of stock $i$. n_Inst and HerfInst are proxies for investor competition as used in Akins, Ng, and Verdi (2012). The natural logarithm is taken for variables that are skewedly distributed. The residual obtained from this regression, $R^{2} R E S$, is used as the first alternative diversification measure. The results are reported in Panel A of Table 9 and are similar to the main results reported in Table 6. For example, when AQ is proxied by $D D$, while the coefficient on innate $\mathrm{AQ} \times D\left(R^{2}{ }_{-} R E S\right)$ is -0.12 and is significant at the $1 \%$ level, the coefficient on discretionary $\mathrm{AQ} \times D\left(R^{2}\right)$ is -0.02 and is insignificant. Therefore, it is unlikely that firm characteristics or investor competition drive my results.

In my main test, I estimate $R^{2}$ based on five-year rolling windows. The purpose is to prevent a potential forward-looking bias. However, Bushee and Goodman (2010) assume that institutional investors' styles do not change over time, and they estimate $R^{2}$ using the full sample period. If this assumption holds, using the full sample period can potentially reduce measurement errors by employing a longer time series. Therefore, I replicate my main tests using the same method as adopted in Bushee and Goodman (2010) (i.e., $R^{2}{ }_{3} B G$ ). As shown in Panel B of Table 9, the results are similar to the main results reported in Table 6. For example, when AQ is proxied by $D D$, while the coefficient on innate $\mathrm{AQ} \times D\left(R_{R}^{2} E S\right)$ is -0.08 and is significant at the $1 \%$ level, the coefficient on innate $\mathrm{AQ} \times D\left(R^{2}\right)$ is -0.02 and is insignificant. Thus, this research design choice does not alter my main findings. 


\section{Chapter 7}

\section{Conclusion}

This dissertation examines whether accounting information risk can be diversified away in the capital market. I find that accounting information risk is priced even if it is entirely idiosyncratic. In particular, when the capital market is under diversified, accounting information risk is priced though it is diversifiable. Furthermore, even if the capital market is well diversified, accounting information risk cannot be diversified away when the information is subject to managers' discretion and thus ambiguous. These results are supported by a model from the ambiguity literature and empirical evidence.

Taken together, this dissertation sheds light on the fundamental question of whether accounting information risk is priced. Contrary to a growing body of studies showing that idiosyncratic information risk can be diversified away, this dissertation shows that accounting information is associated with a non-diversifiable risk and cannot be eliminated. The findings in this dissertation stress a fundamental role of accounting information in the capital market and strengthen our understanding of accounting information. Moreover, the findings in this dissertation emphasize the importance of distinguishing between innate and discretionary information. While both information components are priced in an under-diversified market, only the latter is shown to be associated with a non-diversifiable risk. 
The findings in this dissertation are potentially of interest to practitioners and regulators. Regulators have put considerable effort into improving accounting information quality. This dissertation shows that information risk matters more for stocks held by under-diversified investors. The results suggest that investors are more likely to take information risk into account when they have difficulties in diversifying their portfolios. Therefore, improving information quality appears to be more important for these investors. $^{1}$

Finally, two caveats are in order. First, although the main findings survive in a battery of robustness checks, I acknowledge that the measures in the analysis could suffer from possible measurement errors. My evidence should therefore be interpreted with caution. In addition, my results may be subject to sample truncation bias. For example, the data requirements of implied cost of capital models screen out lesser-known firms with no or weak analyst coverage. However, as these firms are likely to have low accruals quality and a high cost of capital, it is unclear how truncating these firms would affect my results.

\footnotetext{
${ }^{1}$ On average, individual investors are less capable of diversifying their portfolios. The findings in this dissertation are consistent with an emerging literature suggesting that information risk has a bigger impact on individual investors' investment decisions than on institutional investors (Miller, 2010; Lawrence, 2011).
} 


\section{Appendix A}

\section{AQ Related Studies}

The following selection of published papers shows that many researchers continue to view information risk, proxied by accruals quality, is a priced risk factor, despite the fact that it is still debatable that information risk is diversifiable. The papers are listed by the year of publication.

- Bhattacharya, Daouk, and Welker (2003) analyze financial statements from 34 countries. They focus on three dimensions of reported accounting earnings for each country: earnings aggressiveness, loss avoidance, and earnings smoothing. They show that "after controlling for other influences, an increase in overall earnings opacity in a country is linked to an economically significant increase in the cost of equity and an economically significant decrease in trading in the stock market of that country."

- Aboody, Hughes, and Liu (2005) examine (1) whether earnings quality is priced (including AQ as one of their proxies), and (2) whether insider trading is more profitable for firms with higher exposure to earnings quality factor. They conclude that they find "evidence consistent with pricing of the earnings quality factor and insiders trading more profitably in firms with higher exposure to that factor". 
- Chen, Shevlin, and Tong (2007) examine whether accrual earnings quality is a priced information risk factor in a dividend change setting. They use the factormimicking portfolio returns formed on the Dechow-Dichev (2002) accrual quality metric to proxy for the information risk (IR) factor returns. They find that "dividend initiation and increase firms exhibit a decrease in the factor loadings on the IR factor while dividend decrease firms exhibit an increase in the corresponding factor loadings, but such changes in the factor loadings occur months prior to the dividend change announcements" and interpret their results "as being consistent with investors treating the information risk associated with the precision of financial statement information as a priced risk factor".

- Lui, Markov, and Tamayo (2007) examine whether a few stock characteristics impact on analysts' risk ratings. One of the stock characteristics they investigate is earnings quality proxied by accruals quality. Their motivation for focusing on earnings quality comes from their argument that "firms with lower earnings quality have been shown to have higher cost of equity (e.g., Francis et al., 2004 and 2005)". They thus conclude that "idiosyncratic risk, size, book-to-market, leverage, accounting losses, and earnings quality are important determinants of analysts risk ratings. We conclude that financial analysts gather and process information about investment risk in determining the risk ratings".

- Bharath, Sunder, and Sunder (2008) study the role of borrowers' accounting quality in debt contracting. Their arguments are based on the assumption that information risk is priced. Specifically, They state that "an interpretation of our results could be that stringent contract terms for low accounting quality borrowers reflect lenders compensation for information risk. This interpretation is consistent with Easley et al. (2002), Easley and O'Hara (2003), and Francis et al. (2005)". They also mention that their evidence "further supports the hypothesis that information risk 
is a priced source of risk distinct from default risk".

- Francis et al. (2008) examine the link between CEO reputation and earnings quality and show that "reputed CEOs" are associated with higher quality earnings. They claim their results have cost of capital effects because "Francis et al. (2005) and Aboody, Hughes, and Liu (2005) argue that poor earnings quality, as proxied by the Dechow-Dichev (2002) measure of earnings quality and absolute discretionary accruals, is associated with a higher cost of equity and debt capital and greater rents appropriated by insiders. On the basis of these findings, we argue that if reputed CEOs influence earnings quality to make reported earnings look good to maintain their reputations, cost of capital and insider rent appropriation increase".

- Krishnan, Srinidhi, and Su (2008) examine whether inventory policy affects information risk. They show that "accruals quality is systematically poorer for FIFO firms than for LIFO firms ... (and) that the market requires higher returns from FIFO firms, suggesting that the market attaches higher information risk to FIFO firms".

- Ashbaugh-Skaife et al. (2009) examine whether the revelation of SOX internal control deficiencies lowers the reliability of financial reporting, thus increasing information risk that translate into a lower cost of capital. They find that "firms with internal control deficiencies have significantly higher idiosyncratic risk, systematic risk, and cost of equity" and conclude that their "cross-sectional and intertemporal change test results are consistent with internal control reports affecting investors' risk assessments and firms' cost of equity".

- Lee and Masulis (2009) examine the impact of accruals quality on flotation costs during SEOs. They argue that "poor accruals quality by an issuer leads to high information risk, because it raises investor uncertainty and asymmetric information between the issuer and outside investors, which SEO announcements could exac- 
erbate" and find "empirical evidence strongly supporting the hypothesis that poor accruals quality is associated with larger expected flotation costs".

- Kravet and Shevlin (2010) examine the association between accounting restatements and the pricing of information risk. They use "accrual quality to capture information risk and the discretionary component of accrual quality to capture discretionary information risk" and find "an increase in the factor loading on the discretionary information risk factor after restatements consistent with an increase in discretionary information risk".

- Bhattacharya et al. (2012) investigate the direct and indirect links between three measures of earnings quality and the cost of equity. Using path analysis, they conclude that they "find statistically reliable evidence of both a direct path from earnings quality to the cost of equity, and an indirect path that is mediated by information asymmetry, with the weight of the evidence favoring the direct path as the more important".

- Callen, Khan, and Lu (2012) examine whether poor accounting quality is associated with delayed price adjustment to information. Accounting quality is proxied by three measures, one of them is accruals quality. Using the Hou and Moskowitz (2005) metric of price delay, they present evidence that "accounting quality is negatively associated with price delay".

In addition to the above studies that directly rely on the pricing effect of information risk, many papers cite Francis et al.'s (2004, 2005) conclusion that information risk is priced. Several examples are listed below.

- Barton and Mercer (2005): "Recent evidence suggests that information risk is not fully diversifiable and thus affects the firms cost of capital (Botosan 1997; Easley et al. 2002; Francis et al. 2004, 2005)". 
- Brown and Hillegeist (2007): "A growing body of literature reports a negative relation between various measures of disclosure quality and cost of capital estimates (Botosan 1997; Botosan and Plumlee 2002; Francis et al. 2005; Sengupta 1998)".

- Huddart and Ke (2007): "Another source of information risk may be related to earnings quality. Francis et al. (2005) present evidence that accruals quality is a priced risk factor".

- Srinidhi and Gul (2007): "Francis et al. (2005) show that firms with low accrual quality face higher costs of capital because of the need to compensate for the increased information risk that investors face". 


\section{Appendix B}

\section{Proofs}

At date 0, the investor's prior belief of dividend is

$$
d=\mu+\epsilon^{a}+\epsilon^{i}
$$

At date 1, the investor tries to infer the dividend from signal $s=\epsilon^{i}+\epsilon^{s}$.

$$
\begin{gathered}
E\left(\epsilon^{a}+\epsilon^{i} \mid s\right)=\frac{\sigma_{i}^{2}}{\sigma_{i}^{2}+\sigma_{s}^{2}} s=\gamma s \\
\operatorname{Var}\left(\epsilon^{a}+\epsilon^{i} \mid s\right)=\sigma_{a}^{2}+\sigma_{i}^{2}-\frac{\sigma_{i}^{4}}{\sigma_{i}^{2}+\sigma_{s}^{2}}=\sigma_{a}^{2}-(1-\gamma) \sigma_{i}^{2}
\end{gathered}
$$

where $\gamma=\frac{\sigma_{i}^{2}}{\sigma_{i}^{2}+\sigma_{s}^{2}}$.

In Case 1, when the information is innate or $s=s_{F}$, assume that the investor purchases x shares of asset A and y shares of other assets. Because her utility function is $u(c)=e^{-\rho c}$, maximizing her utility at date 0 is equivalent to maximizing the following equation:

$$
\begin{gathered}
\operatorname{Max} u(c) \Leftrightarrow \operatorname{Max} E(c)-\frac{\rho}{2} \operatorname{Var}(c) \\
=\mu x+\tilde{\mu} y-P_{0} x-\tilde{P}_{0} y-\frac{\rho}{2}\left(\left(\sigma_{a}^{2}+\sigma_{i}^{2}\right) x^{2}+\left(\sigma_{a}^{2}+\tilde{\sigma}_{i}^{2}\right) y^{2}+x y \sigma_{a}^{2}\right) .
\end{gathered}
$$

Take the derivative with respect to $\mathrm{x}$ yields

$$
\mu-P_{0}-\rho\left(\sigma_{a}^{2}+\sigma_{i}^{2}\right) x-\rho y \sigma_{a}^{2}=0
$$


Because the investor must hold all assets at equilibrium, $x=\frac{1}{n}, y=\frac{n-1}{n}$. Therefore, the price of asset $\mathrm{A}$ at date 0 is

$$
P_{0}=\mu-\rho\left(\sigma_{a}^{2}+\frac{1}{n} \sigma_{i}^{2}\right)
$$

Therefore, the risk premium or cost of capital at date 0 is

$$
E(R)=E(d)-P_{0}=\rho\left(\sigma_{a}^{2}+\frac{1}{n} \sigma_{i}^{2}\right)
$$

In Case 2, when the information is discretionary or $s=s_{M}$, because the investor is risk-neutral, the price is equal to her expected payoff. Therefore, the price of asset A at date 1 is:

$$
P_{1}=E[d \mid s]=\left\{\begin{array}{lll}
\mu+\bar{\gamma}^{M} s & \text { if } & s>0 \\
\mu+\underline{\gamma}^{M} s & \text { if } & s<0 .
\end{array}\right.
$$

where $\bar{\gamma}^{M}=\frac{\sigma_{i}^{2}}{\sigma_{i}^{2}+\bar{\sigma}_{M}^{2}}, \underline{\gamma}^{M}=\frac{\sigma_{i}^{2}}{\sigma_{i}^{2}+\underline{\sigma}_{M}^{2}}$, and $\bar{\gamma}^{M}<\underline{\gamma}^{M}$. At date 0 , the investor knows that such a signal will arrive at date 1 . Again, because she knows that the manager has incentives to manipulate this information, she will discount the news using the lower precision, i.e., $\bar{\sigma}_{s}^{2}$. Therefore, $s \sim N\left(0, \sigma_{i}^{2}+\bar{\sigma}_{s}^{2}\right)$ and the price of asset A equals to her expected payoff:

$$
P_{0}=E(P 1)=\mu-\frac{\sigma_{i}}{\sqrt{2 \pi \bar{\gamma}}}\left(\underline{\gamma}^{M}-\bar{\gamma}^{M}\right)
$$

Therefore, the risk premium or cost of capital at date 0 is

$$
E(R)=E(d)-P_{0}=\frac{\sigma_{i}}{\sqrt{2 \pi \bar{\gamma}^{M}}}\left(\underline{\gamma}^{M}-\bar{\gamma}^{M}\right)
$$




\section{Appendix C}

\section{EARNings QuALITY MODELS}

This appendix describes two commonly used models to estimate accruals quality. The first model is a modified Dechow and Dichev (2002) model computed as follows:

$$
\begin{aligned}
T C A_{j, t}= & \phi_{0, j}+\phi_{1, j} C F O_{j, t-1}+\phi_{2, j} C F O_{j, t}+\phi_{3, j} C F O_{j, t+1}+\phi_{4, j} \Delta R e v_{j, t} \\
& +\phi_{5, j} P P E_{j, t}+v_{j, t}
\end{aligned}
$$

where :

$T C A=(\triangle C A-\triangle C a s h)-(\triangle C L-\triangle S T D E B T)$

$T A=T C A-D e p$

$\triangle C A=$ change in current assets

$\Delta$ Cash $=$ change in $\operatorname{cash} /$ cash equivalents

$\Delta C L=$ change in current liabilities

$\triangle S T D E B T=$ change in short-term debt

$\Delta D e p=$ Depreciation and amortization expense

$N I B E=$ net income before extraordinary items

$C F O=N I B E-T A$

$\Delta R e v=$ change in revenue 
$P P E=$ gross property, plant, and equipment.

All variables are scaled by average total assets. Eq. C.1 is estimated for each of Fama and French's (1997) 48 industry groups with at least 20 firms in year t. Annual cross-sectional estimations yield firm- and year-specific residuals. $D D_{j, t}=\sigma\left(v_{j}\right)_{t}$ is the standard deviation of firm $j$ 's residuals, $v_{j, t}$, calculated over years t - 4 through t. Larger standard deviations of residuals indicate poorer accruals quality.

The second model is a modified Jones (1991) model computed as follows:

$$
\frac{T A_{j, t}}{\text { Asset }_{j, t-1}}=\kappa_{1} \frac{1}{\text { Asset }_{j, t-1}}+\kappa_{2} \frac{\left(\Delta \operatorname{Rev}_{j, t}-\Delta A R_{j, t}\right)}{\text { Asset }_{j, t-1}}+\kappa_{3} \frac{P P E_{j, t}}{\text { Asset }_{j, t-1}}+\epsilon_{j, t} .
$$

where $\Delta A R_{j, t}$ is firm j's change in accounts receivable between year $\mathrm{t}-1$ and year $\mathrm{t}$. Eq. C.2 is estimated for each of Fama and French's (1997) 48 industry groups with at least 20 firms in year t. The resulting measures of normal accruals and abnormal accruals are: $N A_{j, t}=\hat{\kappa}_{1} \frac{1}{\text { Asset }_{j, t-1}}+\hat{\kappa_{2}} \frac{\left(\Delta \operatorname{Rev}_{j, t}-\Delta A R_{j, t}\right)}{\text { Asset }_{j, t-1}}+\hat{\kappa_{3}} \frac{P P E_{j, t}}{\text { Asset }_{j, t-1}}$, and $A A_{j, t}=T A_{j, t}-N A_{j, t} .\left|A A_{j, t}\right|$ is the absolute value of $A A_{j, t}$ with a greater number indicating poorer accruals quality. 


\section{APPENDIX D}

\section{Implied Cost of CAPital Models}

This appendix describes four accounting valuation models that are used to estimate implied cost of capital in this dissertation.

Claus and Thomas (2001):

$$
P_{i, t}=b p s_{i, t}+\sum_{\tau=1}^{4} \frac{\left(R O E_{i, t+\tau}-r\right) \times b p s_{i, t+\tau-1}}{(1+r)^{\tau}}+\frac{\left(R O E_{i, t+5}-r\right) \times b p s_{i, t+4} \times(1+\gamma)}{(r-\gamma) \times(1+r)^{4}} .
$$

This is a special case of the residual income valuation model. It is assumed that residual income grows at rate $\gamma$ after $T=5$. bps is book value per share, $R O E_{i, t+\tau}=$ $e p s_{i, t+\tau} / b p s_{i, t+\tau-1}, e p s_{i, t+\tau}=e p s_{i, t+2} \times\left(1+l t g_{i}\right)^{\tau-2}$ for $\forall \tau>2, l t g_{i}$ is IBES consensus long term growth rate, $b p s_{i, t+\tau}=b p s_{i, t+\tau-1}+e p s_{i, t+\tau} \times(1-K), \mathrm{K}$ is the payout ratio, and $\gamma$ is the 10-year government bond rate less 3 percent. $r$ or $C O C_{C T}$ is solved via an iterative procedure.

\section{Gebhardt, Lee, and Swaminathan (2001):}

$$
P_{i, t}=b p s_{i, t}+\sum_{\tau=1}^{11} \frac{\left(R O E_{i, t+\tau}-r\right) \times b p s_{i, t+\tau-1}}{(1+r)^{\tau}}+\frac{\left(R O E_{i, t+12}-r\right) \times b p s_{i, t+11}}{(r-\gamma) \times(1+r)^{1} 1} .
$$

This is a special case of the residual income valuation model. It is assumed that residual income converges to industry-specific median return from $T=3$ to $T=12$. From $T=12$ on, residual income is assumed to remain constant. $R O E_{i, t+\tau}=e p s_{i, t+\tau} / b p s_{i, t+\tau-1}$ for 
$\tau=1,2, R O E_{i, t+\tau}=R O E_{i, t+\tau}-$ fade $\forall \tau>2$, fade $=\left(R O E_{i, t-2}-H I R O E_{t}\right)$, HIROE is the industry median from ROE t -4 to $\mathrm{t}, b p s_{i, t+\tau}=b p s_{i, t+\tau-1}+e p s_{i, t+\tau} \times(1-K)$, and $\mathrm{K}$ is the payout ratio. $r$ or $C O C_{G L S}$ is solved via an iterative procedure.

\section{$\operatorname{Easton}(2004)$ :}

$$
P_{i, t}=\frac{e p s_{i, t+2}-e p s_{i, t+1}}{r^{2}}
$$

This model is a special case of the Ohlson and Juettner-Nauroth (2005) model when $T=2$ and $\gamma=0$. It embeds the assumption that growth in abnormal earnings persists in perpetuity after the initial period. Solving for $r$ in this equation yields $C O C_{P E G}$.

\section{Ohlson and Juettner-Nauroth (2005):}

$$
P_{i, t}=\frac{e p s_{i, t+1}}{r}+\frac{e p s_{i, t+2}+r \times d p s_{i, t}-(1+r) \times e p s_{i, t+1}}{r \times(r-\Delta a g r)} .
$$

This model uses one-year-ahead forecasted earnings and dividends per share as well as forecasts of short- and long-term abnormal earnings growth. It is assumed that dividends $(d p s)$ are a constant fraction of forecasted earnings. Long-term growth rate $\Delta a g r$ is set to be the 10-year government bond rate less 3 percent. Solving $r$ in this equation yields $C O C_{O J}$ 


\section{Bibliography}

[1] Abarbanell, J., B. Bushee, and J. Raedy, 2003. Institutional investor preferences and price pressure: The case of corporate spin-offs. The Journal of Business 76 (2): 233-261.

[2] Aboody, D., J. Hughes, and J. Liu, 2005. Earnings quality, insider trading, and cost of capital. Journal of Accounting Research 43 (5): 651-673.

[3] Akins, B. K., J. Ng, and R. S. Verdi, 2012. Investor competition over information and the pricing of information asymmetry. Accounting Review 87 (1): 35-58.

[4] Ali, A., L.-S. Hwang, and M. A. Trombley, 2003. Arbitrage risk and the book-to-market anomaly. Journal of Financial Economics 69 (2): 355-373.

[5] Anilowski, C., M. Feng, and D. J. Skinner, 2007. Does earnings guidance affect market returns? the nature and information content of aggregate earnings guidance. Journal of Accounting and Economics 44 (1?): 36-63.

[6] Anscombe, F. J. and R. J. Aumann, 1963. A definition of subjective probability. The Annals of Mathematical Statistics 34 (1): 199-205.

[7] Armstrong, C. S., J. E. Core, D. J. Taylor, and R. E. Verrecchia, 2011. When does information asymmetry affect the cost of capital? Journal of Accounting Research 49 (1): 1-40.

[8] Ashbaugh-Skaife, H., D. W. Collins, W. R. Kinney Jr, and R. Lafond, 2009. The effect of SOX internal control deficiencies on firm risk and cost of equity. Journal of Accounting Research 47 (1): $1-43$.

[9] Barth, M. E., Y. Konchitchki, and W. R. Landsman, 2011. Cost of capital and earnings transparency. Working Paper, Stanford University and University of North Carolina.

[10] Barth, M. E., Y. Konchitchki, and W. R. Landsman, 2013. Cost of capital and earnings transparency. Journal of Accounting and Economics 55 (2?): 206-224. 
[11] Barton, J. and M. Mercer, 2005. To blame or not to blame: Analysts' reactions to external explanations for poor financial performance. Journal of Accounting and Economics 39 (3): 509533.

[12] Bekaert, G. and C. R. Harvey, 2000. Foreign speculators and emerging equity markets. The Journal of Finance 55 (2): 565-613.

[13] Beyer, A., D. A. Cohen, T. Z. Lys, and B. R. Walther, 2010. The financial reporting environment: Review of the recent literature. Journal of Accounting and Economics 50 (2-3): 296-343.

[14] Bharath, S. T., J. Sunder, and S. V. Sunder, 2008. Accounting quality and debt contracting. Accounting Review 83 (1): 1-28.

[15] Bhattacharya, N., H. Desai, and K. Venkataraman, 2012. Does earnings quality affect information asymmetry: Evidence from trading costs. Contemporary Accounting Research, Forthcoming.

[16] Bhattacharya, N., F. Ecker, P. Olsson, and K. Schipper, 2012. Direct and mediated associations among earnings quality, information asymmetry, and the cost of equity. The Accounting Review 87 (2): 449-482.

[17] Bhattacharya, U., H. Daouk, and M. Welker, 2003. The world price of earnings opacity. The Accounting Review 78 (3): 641-678.

[18] Botosan, C. A. and M. A. Plumlee, 2005. Assessing alternative proxies for the expected risk premium. The Accounting Review 80 (1): 21-53.

[19] Botosan, C. A., M. A. Plumlee, and H. Wen, 2011. The relation between expected returns, realized returns, and firm risk characteristics. Contemporary Accounting Research 28 (4): 1085-1122.

[20] Botosan, C. A., M. A. Plumlee, and Y. Xie, 2004. The role of information precision in determining the cost of equity capital. Review of Accounting Studies 9 (2-3): 233-259.

[21] Brown, S. and S. A. Hillegeist, 2007. How disclosure quality affects the level of information asymmetry. Review of Accounting Studies 12 (2-3): 443-477.

[22] Brown, S. J. and W. N. Goetzmann, 2003. Hedge funds with style. Journal of Portfolio Management 29 (2): 101-112.

[23] Bushee, B. J., 2001. Do institutional investors prefer near-term earnings over long-run value? Contemporary Accounting Research 18 (2): 207-246. 
[24] Bushee, B. J. and T. H. Goodman, 2010. Institutional investor diversification and the pricing of risk. Working Paper, University of Pennsylvania and University of Arizona.

[25] Callen, J. L., M. Khan, and H. Lu, 2012. Accounting quality, stock price delay and future stock returns. Contemporary Accounting Research, Forthcoming.

[26] Camerer, C. and M. Weber, 1992. Recent developments in modeling preferences: Uncertainty and ambiguity. Journal of Risk and Uncertainty 5 (4): 325-370.

[27] Campbell, J. Y., M. Lettau, B. G. Malkiel, and Y. Xu, 2001. Have individual stocks become more volatile: An empirical exploration of idiosyncratic risk. The Journal of Finance 56 (1): 1-43.

[28] Cao, H. H., T. Wang, and H. H. Zhang, 2005. Model uncertainty, limited market participation, and asset prices. Review of Financial Studies 18 (4): 1219-1251.

[29] Caskey, J., J. S. Hughes, and J. Liu, 2012. Strategic informed trades, diversification, and expected returns. Working Paper, University of Texas, UCLA, and UCSD.

[30] Caskey, J. A., 2007. Ambiguous Information and the Demand for Aggregation in Accounting. Ph.D. thesis, University of Michigan.

[31] Chen, C., A. G. Huang, and R. Jha, 2012. Idiosyncratic return volatility and the information quality underlying managerial discretion. Journal of Financial and Quantitative Analysis 47 (4): 873-899.

[32] Chen, S., T. Shevlin, and Y. H. Tong, 2007. Does the pricing of financial reporting quality change around dividend changes? Journal of Accounting Research 45 (1): 1-40.

[33] Chow, C. C. and R. K. Sarin, 2002. Known, unknown, and unknowable uncertainties. Theory and Decision 52 (2): 127-138.

[34] Christensen, P. O., L. E. de la Rosa, and G. A. Feltham, 2010. Information and the cost of capital: An ex ante perspective. The Accounting Review 85 (3): 817-848.

[35] Claus, J. and J. Thomas, 2001. Equity premia as low as three percent: Evidence from analysts' earnings forecasts for domestic and international stock markets. The Journal of Finance 56 (5): $1629-1666$.

[36] Collins, D. W., G. Gong, and P. Hribar, 2003. Investor sophistication and the mispricing of accruals. Review of Accounting Studies 8 (2): 251-276. 
[37] Core, J. E., W. R. Guay, and R. Verdi, 2008. Is accruals quality a priced risk factor? Journal of Accounting and Economics 46 (1): 2-22.

[38] Daniel, K., M. Grinblatt, S. Titman, and R. Wermers, 1997. Measuring mutual fund performance with characteristic-based benchmarks. The Journal of Finance 52 (3): 1035-1058.

[39] Dechow, P. M. and I. D. Dichev, 2002. The quality of accruals and earnings: The role of accrual estimation errors. The Accounting Review 77: 35-59.

[40] Diamond, D. W. and R. E. Verrecchia, 1991. Disclosure, liquidity, and the cost of capital. The Journal of Finance 46 (4): 1325-1359.

[41] Dimson, E., 1979. Risk measurement when shares are subject to infrequent trading. Journal of Financial Economics 7 (2): 197-226.

[42] Duarte, J. and L. Young, 2009. Why is PIN priced? Journal of Financial Economics 91 (2): $119-138$.

[43] Easley, D., S. Hvidkjaer, and M. O'Hara, 2002. Is information risk a determinant of asset returns? The Journal of Finance 57 (5): 2185-2221.

[44] Easley, D. and M. O'Hara, 2004. Information and the cost of capital. The Journal of Finance 59 (4): 1553-1583.

[45] Easley, D. and M. O'Hara, 2010. Microstructure and ambiguity. The Journal of Finance 65 (5): $1817-1846$.

[46] Easton, P. D., 2004. PE ratios, PEG ratios, and estimating the implied expected rate of return on equity capital. The Accounting Review 79 (1): 73-95.

[47] Easton, P. D. and S. J. Monahan, 2005. An evaluation of accounting-based measures of expected returns. Accounting Review 80 (2): 501-538.

[48] Easton, P. D. and G. A. Sommers, 2007. Effect of analysts' optimism on estimates of the expected rate of return implied by earnings forecasts. Journal of Accounting Research 45 (5): 983-1015.

[49] Ellsberg, D., 1961. Risk, ambiguity, and the savage axioms. The Quarterly Journal of Economics 75 (4): 643-669.

[50] Elton, E. J., 1999. Presidential address: Expected return, realized return, and asset pricing tests. The Journal of Finance 54 (4): 1199-1220. 
[51] Epstein, L. G. and J. Miao, 2003. A two-person dynamic equilibrium under ambiguity. Journal of Economic Dynamics and Control 27 (7): 1253-1288.

[52] Epstein, L. G. and M. Schneider, 2003. Recursive multiple-priors. Journal of Economic Theory 113 (1): $1-31$.

[53] Epstein, L. G. and M. Schneider, 2008. Ambiguity, information quality, and asset pricing. The Journal of Finance 63 (1): 197-228.

[54] Faccio, M., M.-T. Marchica, and R. Mura, 2011. Large shareholder diversification and corporate risk-taking. Review of Financial Studies 24 (11): 3601-3641.

[55] Fama, E. F., 1991. Efficient capital markets: II. The Journal of Finance 46 (5): 1575-1617.

[56] Fama, E. F. and K. R. French, 1992. The cross-section of expected stock returns. Journal of Finance 47 (2): 427-65.

[57] Fama, E. F. and K. R. French, 1997. Industry costs of equity. Journal of Financial Economics 43 (2): 153-193.

[58] Fama, E. F. and K. R. French, 2007. Disagreement, tastes, and asset prices. Journal of Financial Economics 83 (3): 667-689.

[59] Fama, E. F. and J. D. MacBeth, 1973. Risk, return, and equilibrium: Empirical tests. The Journal of Political Economy 81 (3): 607-636.

[60] Fox, C. R. and A. Tversky, 1995. Ambiguity aversion and comparative ignorance. The Quarterly Journal of Economics 110 (3): 585-603.

[61] Francis, J., A. H. Huang, S. Rajgopal, and A. Y. Zang, 2008. CEO reputation and earnings quality. Contemporary Accounting Research 25 (1): 109-147.

[62] Francis, J., R. LaFond, P. Olsson, and K. Schipper, 2004. Costs of equity and earnings attributes. The Accounting Review 79 (4): 967-1010.

[63] Francis, J., R. LaFond, P. Olsson, and K. Schipper, 2005. The market pricing of accruals quality. Journal of Accounting and Economics 39 (2): 295-327.

[64] Francis, J., D. Nanda, and P. Olsson, 2008. Voluntary disclosure, earnings quality, and cost of capital. Journal of Accounting Research 46 (1): 53-99.

[65] Francis, J. R., I. K. Khurana, and R. Pereira, 2005. Disclosure incentives and effects on cost of capital around the world. Accounting Review 80 (4): 1125-1162. 
[66] Fu, F., 2009. Idiosyncratic risk and the cross-section of expected stock returns. Journal of Financial Economics 91 (1): 24-37.

[67] Gebhardt, W. R., C. M. C. Lee, and B. Swaminathan, 2001. Toward an implied cost of capital. Journal of Accounting Research 39 (1): 135-176.

[68] Gilboa, I., 2009. Theory of decision under uncertainty. Cambridge books, Cambridge University Press.

[69] Gilboa, I. and D. Schmeidler, 1989. Maxmin expected utility with non-unique prior. Journal of Mathematical Economics 18 (2): 141-153.

[70] Gode, D. and P. Mohanram, 2003. Inferring the cost of capital using the ohlson-juettner model. Review of Accounting Studies 8 (4): 399-431.

[71] Goetzmann, W. N. and A. Kumar, 2008. Equity portfolio diversification. Review of Finance 12 (3): 433-463.

[72] Graham, J. R., C. R. Harvey, and S. Rajgopal, 2005. The economic implications of corporate financial reporting. Journal of Accounting and Economics 40 (1): 3-73.

[73] Grossman, S. J. and J. E. Stiglitz, 1980. On the impossibility of informationally efficient markets. The American Economic Review 70 (3): 393-408.

[74] Guay, W., S. P. Kothari, and S. Shu, 2011. Properties of implied cost of capital using analysts' forecasts. Australian Journal of Management 36 (2): 125-149.

[75] Hail, L. and C. Leuz, 2006. International differences in the cost of equity capital: Do legal institutions and securities regulation matter? Journal of Accounting Research 44 (3): 485-531.

[76] Hail, L. and C. Leuz, 2009. Cost of capital effects and changes in growth expectations around U.S. cross-listings. Journal of Financial Economics 93 (3): 428-454.

[77] Halevy, Y., 2007. Ellsberg revisited: An experimental study. Econometrica 75 (2): 503-536.

[78] Hand, J. R. M., 1990. A test of the extended functional fixation hypothesis. Accounting Review 65 (4): $740-763$.

[79] Healy, P. M. and J. M. Wahlen, 1999. A review of the earnings management literature and its implications for standard setting. Accounting Horizons 13 (4): 365-383.

[80] Huang, W., Q. Liu, S. G. Rhee, and L. Zhang, 2010. Return reversals, idiosyncratic risk, and expected returns. Review of Financial Studies 23 (1): 147-168. 
[81] Huddart, S. J. and B. Ke, 2007. Information asymmetry and cross-sectional variation in insider trading. Contemporary Accounting Research 24 (1): 195-232.

[82] Hughes, J., J. Liu, and W. Su, 2008. On the relation between predictable market returns and predictable analyst forecast errors. Review of Accounting Studies 13 (2-3): 266-291.

[83] Hughes, J. S., J. Liu, and J. Liu, 2007. Information asymmetry, diversification, and cost of capital. Accounting Review 82 (3): 705-729.

[84] Hutton, A. P., G. S. Miller, and D. J. Skinner, 2003. The role of supplementary statements with management earnings forecasts. Journal of Accounting Research 41 (5): 867-890.

[85] Indjejikian, R. J., 2007. Discussion of accounting information, disclosure, and the cost of capital. Journal of Accounting Research 45 (2): 421-426.

[86] Izhakian, Y., 2012. Does ambiguity diversification pay? Working Paper, New York University.

[87] Jennings, R., 1987. Unsystematic security price movements, management earnings forecasts, and revisions in consensus analyst earnings forecasts. Journal of Accounting Research 25 (1): 90-110.

[88] Jiambalvo, J., S. Rajgopal, and M. Venkatachalam, 2002. Institutional ownership and the extent to which stock prices reflect future earnings. Contemporary Accounting Research 19 (1): 117-145.

[89] Jones, J. J., 1991. Earnings management during import relief investigations. Journal of Accounting Research 29 (2): 193-228.

[90] Karni, E. and D. Schmeidler, 1991. Chapter 33 utility theory with uncertainty. In Werner Hildenbrand and Hugo Sonnenschein, editor, Handbook of Mathematical Economics, volume Volume 4, 1763-1831. Elsevier.

[91] Keynes, J. M., 1921. A Treatise on Probability, volume 3. London: Macmillan.

[92] Kim, D. and Y. Qi, 2010. Accruals quality, stock returns, and macroeconomic conditions. Accounting Review 85 (3): 937-978.

[93] Klibanoff, P., M. Marinacci, and S. Mukerji, 2005. A smooth model of decision making under ambiguity. Econometrica 73 (6): 1849-1892.

[94] Knight, H. F., 1921. Risk, Uncertainty, and Profit. Boston, MA: Houghton Miffiin.

[95] Kravet, T. and T. Shevlin, 2010. Accounting restatements and information risk. Review of Accounting Studies 15 (2): 264-294. 
[96] Krishnan, G. V., B. Srinidhi, and L. N. Su, 2008. Inventory policy, accruals quality and information risk. Review of Accounting Studies 13 (2-3): 369-410.

[97] Kumar, A., 2007. Do the diversification choices of individual investors influence stock returns? Journal of Financial Markets 10 (4): 362-390.

[98] Lambert, R., C. Leuz, and R. E. Verrecchia, 2007. Accounting information, disclosure, and the cost of capital. Journal of Accounting Research 45 (2): 385-420.

[99] Lambert, R., C. Leuz, and R. E. Verrecchia, 2012. Information asymmetry, information precision, and the cost of capital. Review of Finance 16 (1): 1-29.

[100] Larocque, S., 2013. Analysts' earnings forecast errors and cost of equity capital estimates. Review of Accounting Studies, 18 (1): 135-166.

[101] Lawrence, A., 2011. Individual Investors and Financial Disclosure. Ph.D. thesis, University of Toronto.

[102] Lee, G. and R. W. Masulis, 2009. Seasoned equity offerings: Quality of accounting information and expected flotation costs. Journal of Financial Economics 92 (3): 443-469.

[103] Levy, H., 1978. Equilibrium in an imperfect market: A constraint on the number of securities in the portfolio. The American Economic Review 68 (4): 643-658.

[104] Lui, D., S. Markov, and A. Tamayo, 2007. What makes a stock risky? evidence from sell-side analysts' risk ratings. Journal of Accounting Research 45 (3): 629-665.

[105] Mankiw, N. and S. P. Zeldes, 1991. The consumption of stockholders and nonstockholders. Journal of Financial Economics 29 (1): 97-112.

[106] Marschak, J. and K. Miyasawa, 1968. Economic comparability of information systems. International Economic Review 9 (2): 137-175.

[107] Mashruwala, C. A. and S. D. Mashruwala, 2011. The pricing of accruals quality: January versus the rest of the year. The Accounting Review 86 (4): 1349-1381.

[108] McNichols, M. F., 2002. Discussion of the quality of accruals and earnings: The role of accrual estimation errors. The Accounting Review 77 (1): 61-69.

[109] Merton, R. C., 1987. A simple model of capital market equilibrium with incomplete information. Journal of Finance 42 (3): 483-510. 
[110] Miller, B. P., 2010. The effects of reporting complexity on small and large investor trading. Accounting Review 85 (6): 2107-2143.

[111] Miller, G. S. and D. J. Skinner, 1998. Determinants of the valuation allowance for deferred tax assets under SFAS no. 109. Accounting Review 213-233.

[112] Modigliani, F. and M. H. Miller, 1958. The cost of capital, corporation finance and the theory of investment. American Economic Review 48 (3): 261-298.

[113] Mohanram, P. and D. Gode, 2013. Removing predictable analyst forecast errors to improve implied cost of equity estimates. Review of Accounting Studies 18 (2): 443-478.

[114] Mohanram, P. and S. Rajgopal, 2009. Is pin priced risk? Journal of Accounting and Economics 47 (3): $226-243$.

[115] Ogneva, M., 2012. Accrual quality, realized returns, and expected returns: The importance of controlling for cash flow shocks. The Accounting Review 87 (4): 1415-1444.

[116] Ohlson, J. A. and B. E. Juettner-Nauroth, 2005. Expected EPS and EPS growth as determinantsof value. Review of Accounting Studies 10 (2-3): 349-365.

[117] Piotroski, J. D. and D. T. Roulstone, 2004. The influence of analysts, institutional investors, and insiders on the incorporation of market, industry, and firm-specific information into stock prices. The Accounting Review 79 (4): 1119-1151.

[118] Rajgopal, S. and M. Venkatachalam, 2011. Financial reporting quality and idiosyncratic return volatility. Journal of Accounting and Economics 51 (1-2): 1-20.

[119] Sarin, R. K. and M. Weber, 1993. Effects of ambiguity in market experiments. Management Science 39 (5): 602-615.

[120] Savage, L. J., 1954. The foundations of statistics, volume xv. John Wiley \& Sons, Oxford, England.

[121] Schrand, C. M. and M. H. F. Wong, 2003. Earnings management using the valuation allowance for deferred tax assets under SFAS no. 109. Contemporary Accounting Research 20 (3): 579-611.

[122] Sengupta, P., 1998. Corporate disclosure quality and the cost of debt. The Accounting Review 73 (4): 459-474.

[123] Shumway, T., 1997. The delisting bias in CRSP data. Journal of Finance 52 (1): 327-40.

[124] Shumway, T. and V. A. Warther, 1999. The delisting bias in CRSP's nasdaq data and its implications for the size effect. The Journal of Finance 54 (6): 2361-2379. 
[125] Skinner, D. and R. Sloan, 2002. Earnings surprises, growth expectations, and stock returns or don't let an earnings torpedo sink your portfolio. Review of Accounting Studies 7 (2): 289-312.

[126] Smith, M. P., 1996. Shareholder activism by institutional investors: Evidence from CalPERS. The Journal of Finance 51 (1): 227-252.

[127] Uppal, R., 1963. Model misspecification and underdiversification. The Journal of Finance 58 (6): $2465-2486$.

[128] Von Neumann, J. and O. Morgenstern, 1947. Theory of games and economic behavior (2d rev. ed.), volume xviii. Princeton University Press, Princeton, NJ, US.

[129] Wakker, P., 1993. Unbounded utility for savage's "Foundations of statistics," and other models. Mathematics of Operations Research 18 (2): 446-485.

[130] Williams, C. D., 2009. Asymmetric responses to good and bad news: An empirical case for ambiguity. Working Paper, University of Michigan.

[131] Williams, P. A., 1996. The relation between a prior earnings forecast by management and analyst response to a current management forecast. The Accounting Review 71 (1): 103-115.

[132] Xin, B., 2008. Earnings forecast, earnings management, and asymmetric price response. Working Paper, University of Toronto.

[133] Yee, K. K., 2006. Earnings quality and the equity risk premium: A benchmark model. Contemporary Accounting Research 23 (3): 833-877. 


\section{Table 1: Variable Descriptive Statistics for the Pooled Sample}

This table reports the pooled descriptive statistics of non-financial firms that are traded on the NYSE, Amex, or Nasdaq exchanges during the period 1982 to 2010. COC $C$, $C O C_{G L S}, C O C_{P E G}, C O C_{O J}$, and $C O C_{O J}$ are implied cost of capital estimates imputed from four commonly used accounting valuation models. $C O C_{A V G}$ is the average of the above four estimates used in the prior literature. $D D$ and $|A A|$ are accruals quality metrics based on a modified Dechow and Dichev (2002) model and a modified Jones (1991) model, respectively. These two metrics are further decomposed into innate and discretionary components. $R^{2}$ is the proxy for diversification, estimated using institutional information over five-year rolling windows. The procedure is described in Section 4.3. BET A is the portfolio beta as constructed in Fama and French (1992). $M E$ is the market value of equity - the product of monthly closing price and outstanding share numbers in June of the previous year. Book-to-market equity $(B E / M E)$ is constructed as the fiscal year-end book value of common equity divided by the calendar year-end market value of equity. Lev is the ratio of long-term debt to total assets. $M M T$ is the logarithm of one plus the compounded returns over the previous 12 months. FBIAS is the one-year-ahead forecast error (forecast minus actual value) deflated by lagged price. To avoid giving extreme observations heavy weight in the return regressions and potential data-recording errors, the smallest and largest $1 \%$ of the observations in each year for all variables are set equal to the next smallest or largest values, respectively. 


\begin{tabular}{|c|c|c|c|c|c|c|}
\hline Variable & Mean & Median & S.D. & Q1 & Q3 & $\mathrm{N}$ \\
\hline \multicolumn{7}{|l|}{ Panel A } \\
\hline$C O C_{C T}(\%)$ & 11.45 & 10.39 & 5.47 & 8.46 & 12.79 & 47854 \\
\hline$C O C_{G L S}(\%)$ & 11.13 & 10.86 & 3.36 & 9.09 & 12.85 & 47854 \\
\hline$C O C_{P E G}(\%)$ & 11.81 & 11.09 & 4.08 & 9.30 & 13.41 & 47854 \\
\hline$C O C_{O J}(\%)$ & 12.29 & 11.06 & 5.25 & 8.86 & 14.56 & 47854 \\
\hline$C O C_{A V G}(\%)$ & 11.65 & 10.90 & 3.61 & 9.28 & 13.10 & 47854 \\
\hline \multicolumn{7}{|l|}{ Panel B } \\
\hline$D D(\%)$ & 3.84 & 3.05 & 2.97 & 1.79 & 4.96 & 36540 \\
\hline Innate $D D(\%)$ & 3.78 & 3.30 & 2.41 & 2.06 & 4.95 & 32410 \\
\hline $\operatorname{DiscDD}(\%)$ & -0.04 & -0.14 & 1.89 & -1.02 & 0.77 & 32410 \\
\hline$|A A|(\%)$ & 5.82 & 3.88 & 6.47 & 1.68 & 7.55 & 45727 \\
\hline Innate $|A A|(\%)$ & 5.61 & 4.92 & 3.78 & 2.97 & 7.41 & 39810 \\
\hline $\operatorname{Disc}|A A|(\%)$ & 0.11 & -0.54 & 5.54 & -2.92 & 2.25 & 39810 \\
\hline$R^{2}$ & 0.88 & 0.90 & 0.06 & 0.86 & 0.93 & 47854 \\
\hline \multicolumn{7}{|l|}{ Panel C } \\
\hline BETA & 1.26 & 1.24 & 0.35 & 1.01 & 1.48 & 47854 \\
\hline $\operatorname{Ln}(M E)$ & 6.25 & 6.18 & 1.74 & 4.97 & 7.41 & 47854 \\
\hline $\operatorname{Ln}(B E / M E)$ & -0.62 & -0.64 & 0.96 & -1.15 & -0.18 & 47854 \\
\hline$L e v$ & 0.22 & 0.22 & 0.17 & 0.07 & 0.34 & 47854 \\
\hline$M M T$ & 0.09 & 0.10 & 0.39 & -0.13 & 0.32 & 47854 \\
\hline$F B I A S(\%)$ & 0.89 & 0.14 & 6.62 & -0.32 & 1.52 & 47854 \\
\hline
\end{tabular}




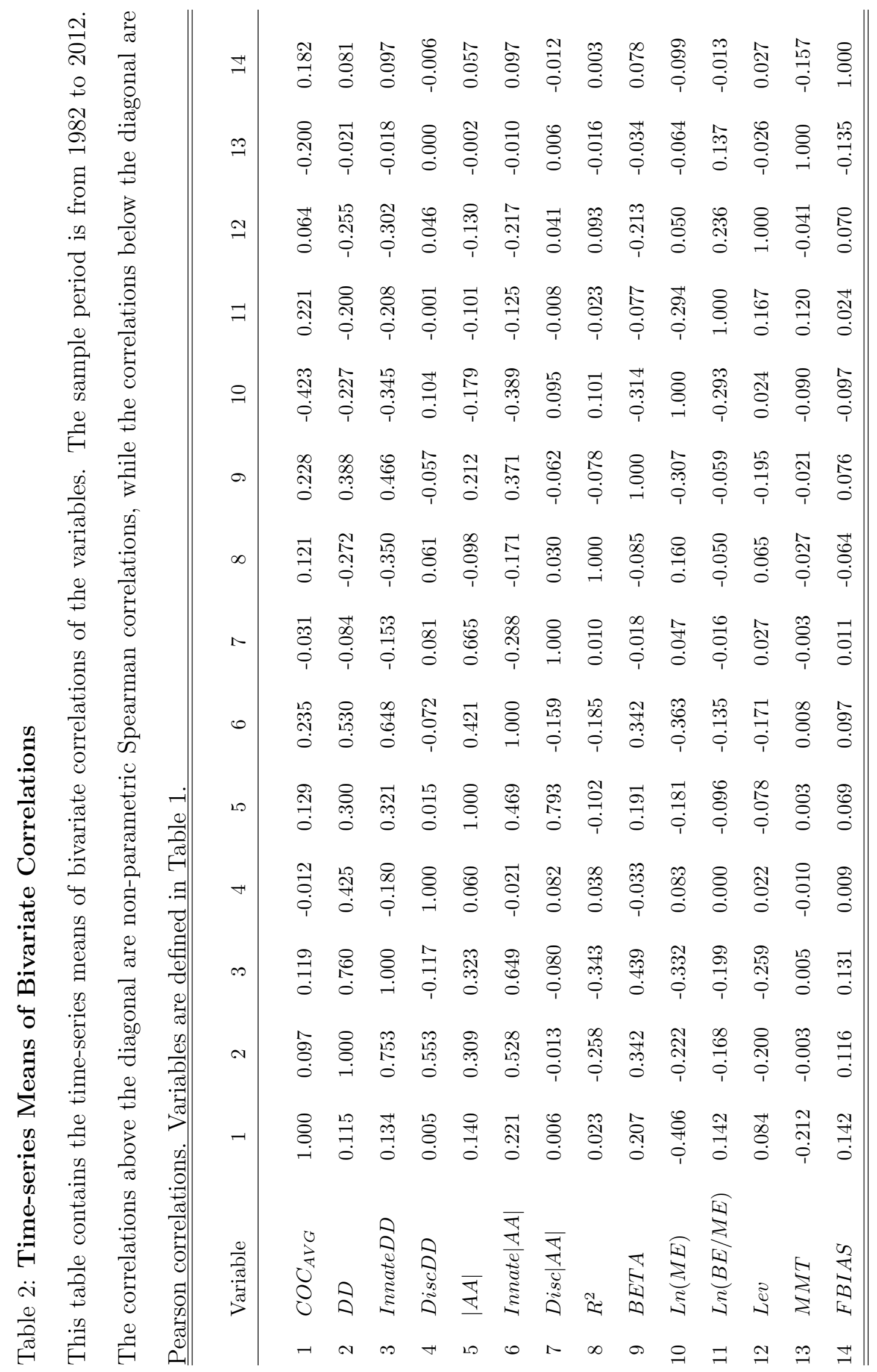




\section{Table 3: Independent Sort Performance of $D D$ and $R^{2}$}

This table reports the implied cost of capital of portfolios independently double-sorted by $D D$ and $R^{2}$. Implied cost of capital estimates are the average of the implied cost of capital imputed from four commonly used accounting valuation models, i.e., $C O C_{A V G}$. The diversification proxy, $R^{2}$, is estimated using institutional information over five-year rolling windows. The procedure is described in Section 4.3. Panel A presents value weighted average of Risk Premium (i.e., $C O C_{A V G}-R_{f}$ ), and Panel B presents the valueweighted average after adjusting for the Fama-French three factors, i.e., the Fama-French Alpha. The sample period is from 1982 to 2010. *, **, and *** indicate two-tailed significance at the $1 \%, 5 \%$, and $10 \%$ levels, respectively. 
Panel A: Risk Premium (\%)

\begin{tabular}{|c|c|c|c|c|c|}
\hline \multirow[b]{2}{*}{$D D$} & \multicolumn{5}{|c|}{ Quintiles formed on $R^{2}$} \\
\hline & Low & 2 & 3 & 4 & High \\
\hline Low (Best) & 3.49 & 3.54 & 3.58 & 3.54 & 3.25 \\
\hline 2 & 3.67 & 3.87 & 3.88 & 3.63 & 3.19 \\
\hline 3 & 3.53 & 3.85 & 4.37 & 3.83 & 3.33 \\
\hline 4 & 4.31 & 4.72 & 4.35 & 4.06 & 3.53 \\
\hline High (Worst) & 4.82 & 4.81 & 4.53 & 4.13 & 3.89 \\
\hline High - Low & $\begin{array}{c}1.33^{* * *} \\
(2.69)\end{array}$ & $\begin{array}{c}1.27 * * * \\
(2.35)\end{array}$ & $\begin{array}{c}0.96 * * * \\
(2.65)\end{array}$ & $\begin{array}{c}0.59^{* *} \\
(2.74)\end{array}$ & $\begin{array}{c}0.64^{* * *} \\
(2.43)\end{array}$ \\
\hline
\end{tabular}

Panel B: Fama-French Alpha (\%)

\begin{tabular}{|c|c|c|c|c|c|}
\hline \multirow[b]{2}{*}{$D D$} & \multicolumn{5}{|c|}{ Quintiles formed on $R^{2}$} \\
\hline & Low & 2 & 3 & 4 & High \\
\hline Low (Best) & 2.30 & 2.31 & 2.42 & 2.39 & 2.19 \\
\hline 2 & 2.45 & 2.91 & 2.87 & 2.64 & 2.23 \\
\hline 3 & 2.43 & 2.87 & 3.24 & 2.79 & 2.48 \\
\hline 4 & 3.37 & 3.70 & 3.41 & 3.00 & 2.59 \\
\hline High (Worst) & 3.91 & 3.87 & 3.55 & 3.32 & 3.21 \\
\hline High - Low & $\begin{array}{c}1.61 * * * \\
(5.54)\end{array}$ & $\begin{array}{c}1.56^{* * *} \\
(5.56)\end{array}$ & $\begin{array}{c}1.13^{* * *} \\
(4.18)\end{array}$ & $\begin{array}{c}0.93^{* * *} \\
(4.04)\end{array}$ & $\begin{array}{c}1.01 * * * \\
(4.70)\end{array}$ \\
\hline
\end{tabular}


Table 4: Independent Sort Performance of $|A A|$ and $R^{2}$

This table reports the implied cost of capital of portfolios independently double-sorted by $|A A|$ and $R^{2}$. Implied cost of capital estimates are the average of the implied cost of capital imputed from four commonly used accounting valuation models, i.e., $C O C_{A V G}$. The diversification proxy, $R^{2}$, is estimated using institutional information over five-year rolling windows. The procedure is described in Section 4.3. Panel A presents value weighted average of Risk Premium (i.e., $C O C_{A V G}-R_{f}$ ), and Panel B presents the valueweighted average after adjusting for the Fama-French three factors, i.e., the Fama-French Alpha. The sample period is from 1982 to 2010. *, **, and *** indicate two-tailed significance at the $1 \%, 5 \%$, and $10 \%$ levels, respectively. 
Panel A: Risk Premium (\%)

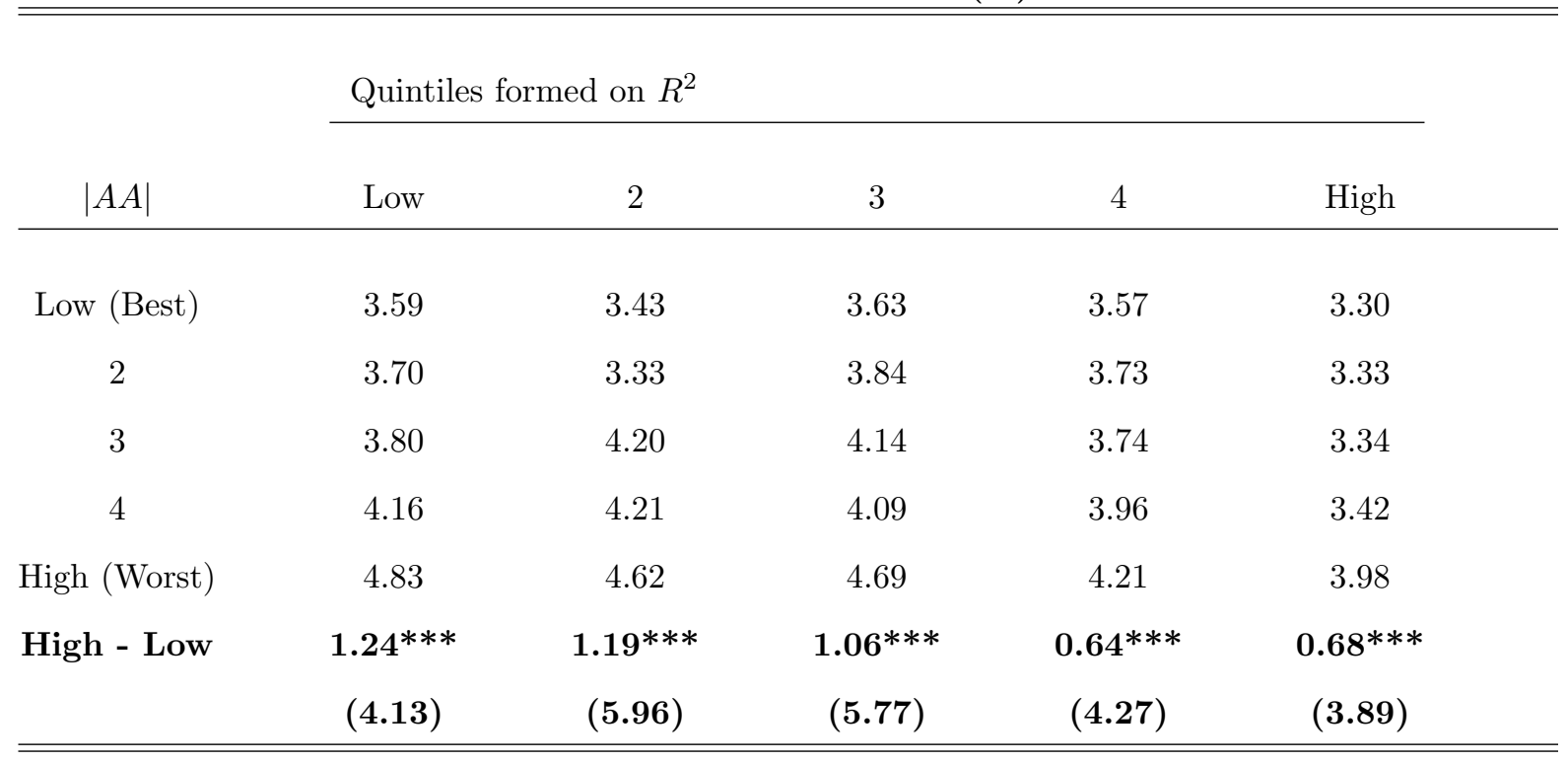

Panel B: Fama-French Alpha (\%)

\begin{tabular}{|c|c|c|c|c|c|}
\hline \multirow[b]{2}{*}{$|A A|$} & \multicolumn{5}{|c|}{ Quintiles formed on $R^{2}$} \\
\hline & Low & 2 & 3 & 4 & High \\
\hline Low (Best) & 2.46 & 2.67 & 2.62 & 2.61 & 2.38 \\
\hline 2 & 2.62 & 2.41 & 2.91 & 2.76 & 2.40 \\
\hline 3 & 2.95 & 3.16 & 3.17 & 2.86 & 2.47 \\
\hline 4 & 3.24 & 3.27 & 3.28 & 2.99 & 2.49 \\
\hline High (Worst) & 4.04 & 3.88 & 3.81 & 3.54 & 3.29 \\
\hline High - Low & $\begin{array}{c}1.58^{* * *} \\
(5.01)\end{array}$ & $\begin{array}{c}1.21 * * * \\
(4.16)\end{array}$ & $\begin{array}{c}1.19 * * * \\
(5.88)\end{array}$ & $\begin{array}{c}0.93^{* * *} \\
(5.72)\end{array}$ & $\begin{array}{c}0.90 * * * \\
(4.50)\end{array}$ \\
\hline
\end{tabular}




\section{Table 5: Fama-MacBeth Regressions of Implied Cost of Capital on Accruals Quality Metrics}

This table presents the time-series averages of the slopes in cross-sectional regressions using standard Fama and MacBeth (1973) methodology. The sample period is from 1982 to 2010. The dependent variable $\left(C O C_{A V G}\right)$ is the average of implied cost of capital imputed from four commonly used accounting-valuation models. $D D$ and $|A A|$ are accruals quality metrics based on a modified Dechow and Dichev (2002) model and a modified Jones (1991) model, respectively. These two metrics are further decomposed into innate and discretionary components by two approaches. The first approach explicitly separates the innate and discretionary components of accruals quality using annual regressions of AQ on the innate factors. The second approach controls for innate factors affecting accruals quality by including them in the regression. Innate Factors are defined in Eq. 4.1 following Francis et al. (2005). Their coefficients in the regressions are not tabulated but are available upon request. BET $A$ is the portfolio beta as constructed in Fama and French (1992). $M E$ is the market value of equity - the product of monthly closing price and outstanding share numbers in June of the previous year. Book-to-market equity $(B E / M E)$ is constructed as the fiscal-year-end book value of common equity divided by the calendar year-end market value of equity. $M M T$ is the logarithm of one plus the compounded returns over the previous 12 months. FBIAS is the one-year-ahead forecast error (forecast minus actual value) deflated by lagged price. To avoid giving extreme observations heavy weight in the return regressions and potential data recording errors, the smallest and largest $1 \%$ of the observations in each year for all variables are set equal to the next smallest or largest values. Newey and West (1987) robust t-statistics are reported in parentheses. * $* *$, and $* * *$ indicate two-tailed significance at the $1 \%, 5 \%$, and $10 \%$ levels, respectively. 


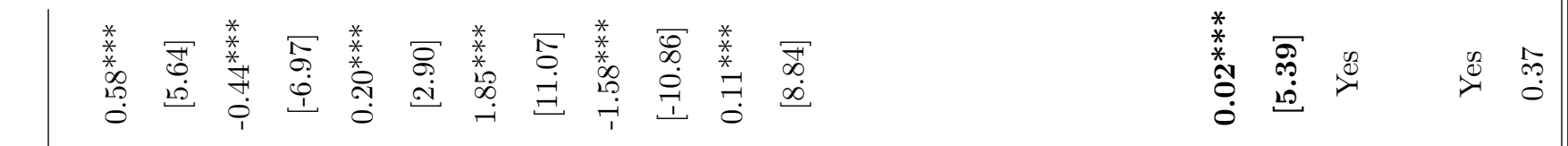

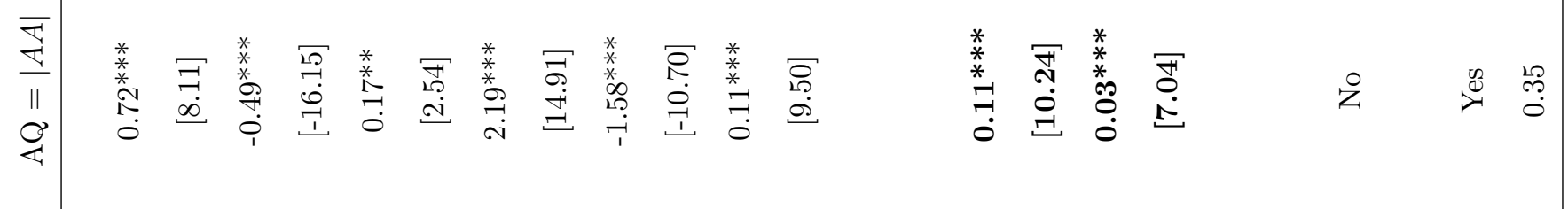

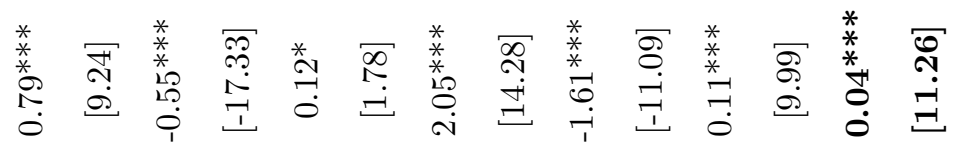

$$
\begin{aligned}
& \text { 台串哭 }
\end{aligned}
$$

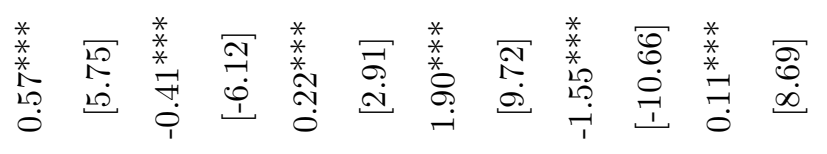

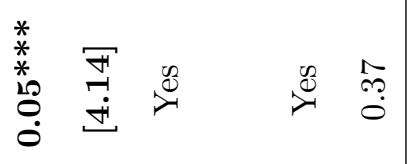

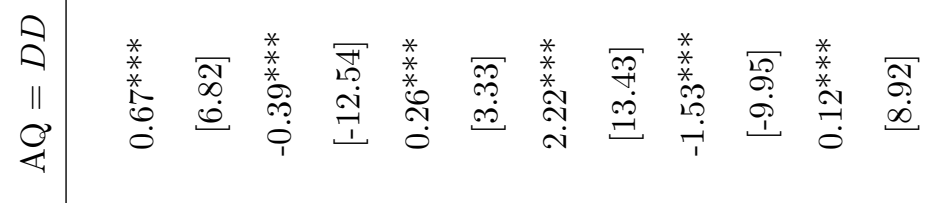

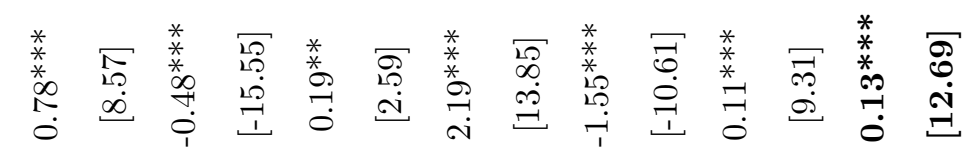

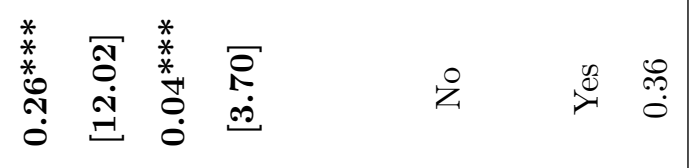

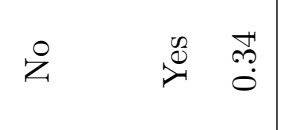

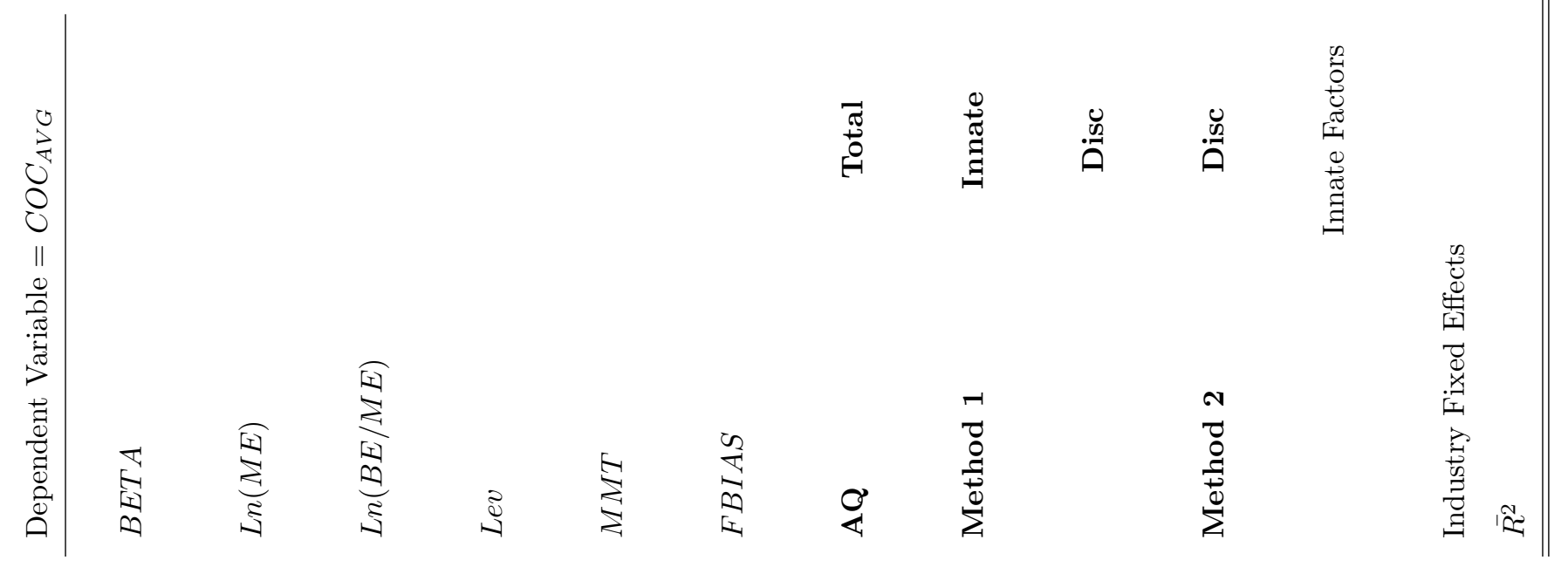


Table 6: The Influence of Diversification on the Pricing of Accruals Quality

This table presents the time-series averages of the slopes in cross-sectional regressions (Eq. 5.2) using the standard Fama and MacBeth (1973) methodology. The dependent variable $\left(C O C_{A V G}\right)$ is the average of four implied cost of capital estimates imputed from commonly used accounting-valuation models. $D D$ and $|A A|$ are accruals quality metrics based on a modified Dechow and Dichev (2002) model and a modified Jones (1991) model, respectively. These two metrics are further decomposed into innate and discretionary components by two approaches. The first approach explicitly separates the innate and discretionary components of accruals quality using annual regressions of $\mathrm{AQ}$ on the innate factors. The second approach controls for innate factors affecting accruals quality by including them in the regression. Innate Factors are defined in Eq. 4.1 following Francis et al. (2005). Their coefficients in the regressions are not tabulated but are available upon request. $D\left(R^{2}\right)$ is the decile rank of $D\left(R^{2}\right)$, proxying for the extent of diversification. $R^{2}$ is estimated using institutional information over five-year rolling windows. The procedure is described in Section 4.3. BETA is the portfolio beta as constructed in Fama and French (1992). $M E$ is the market value of equity - the product of monthly closing price and outstanding share numbers in June of the previous year. Book-to-market equity $(B E / M E)$ is constructed as the fiscal-year-end book value of common equity divided by the calendar year-end market value of equity. Lev is the ratio of long-term debt to total assets. MMT is the logarithm of one plus the compounded returns over the previous 12 months. FBIAS is the one-year-ahead forecast error (forecast minus actual value) deflated by lagged price. To avoid giving extreme observations heavy weight in the return regressions and potential data recording errors, the smallest and largest $1 \%$ of the observations in each year for all variables are set equal to the next smallest or largest values. Newey and West (1987) robust t-statistics are reported in parentheses. * , **, and *** indicate two-tailed significance at the $1 \%$, $5 \%$, and $10 \%$ levels, respectively. 


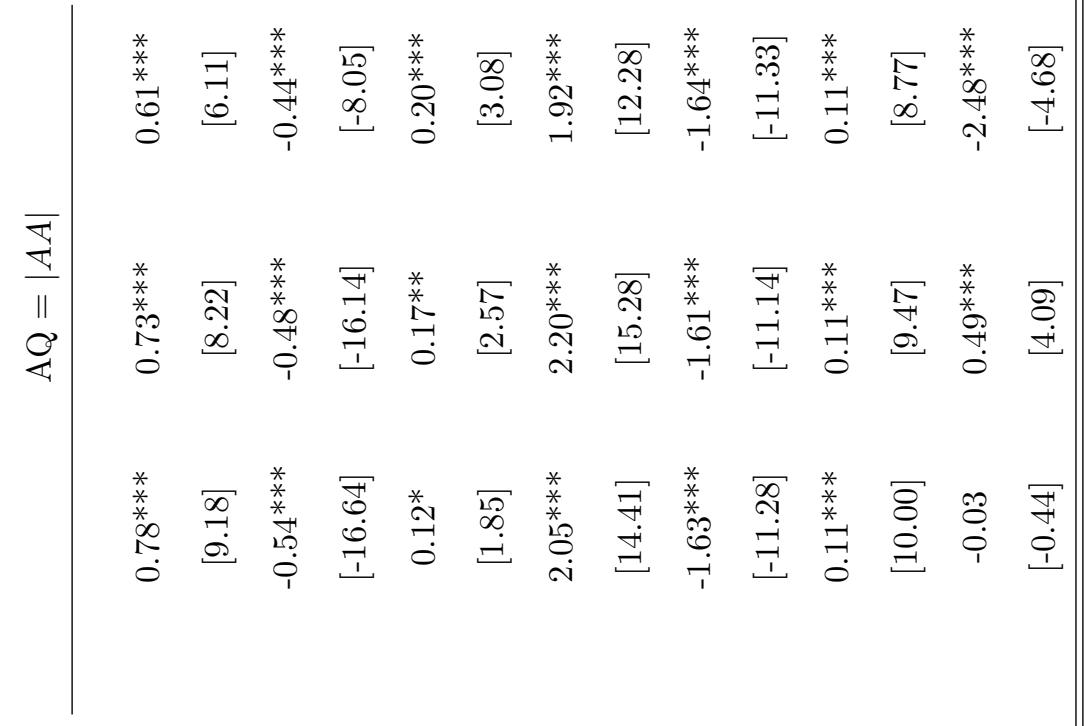

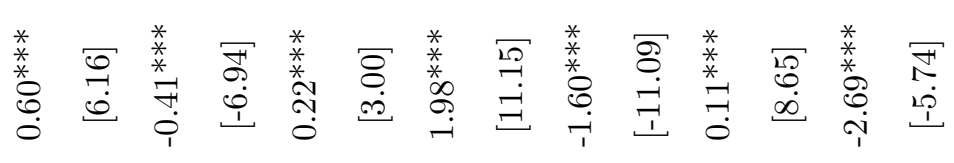

ลิ

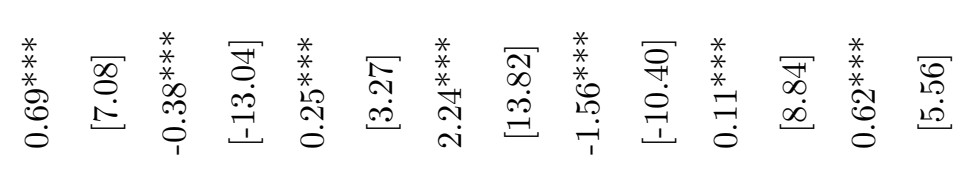

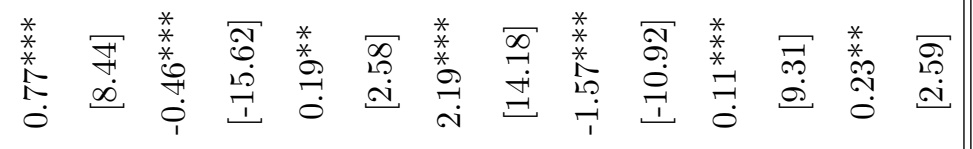

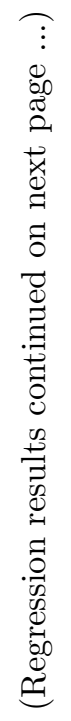

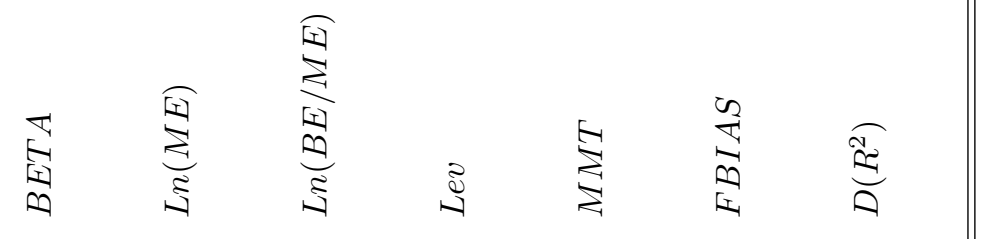




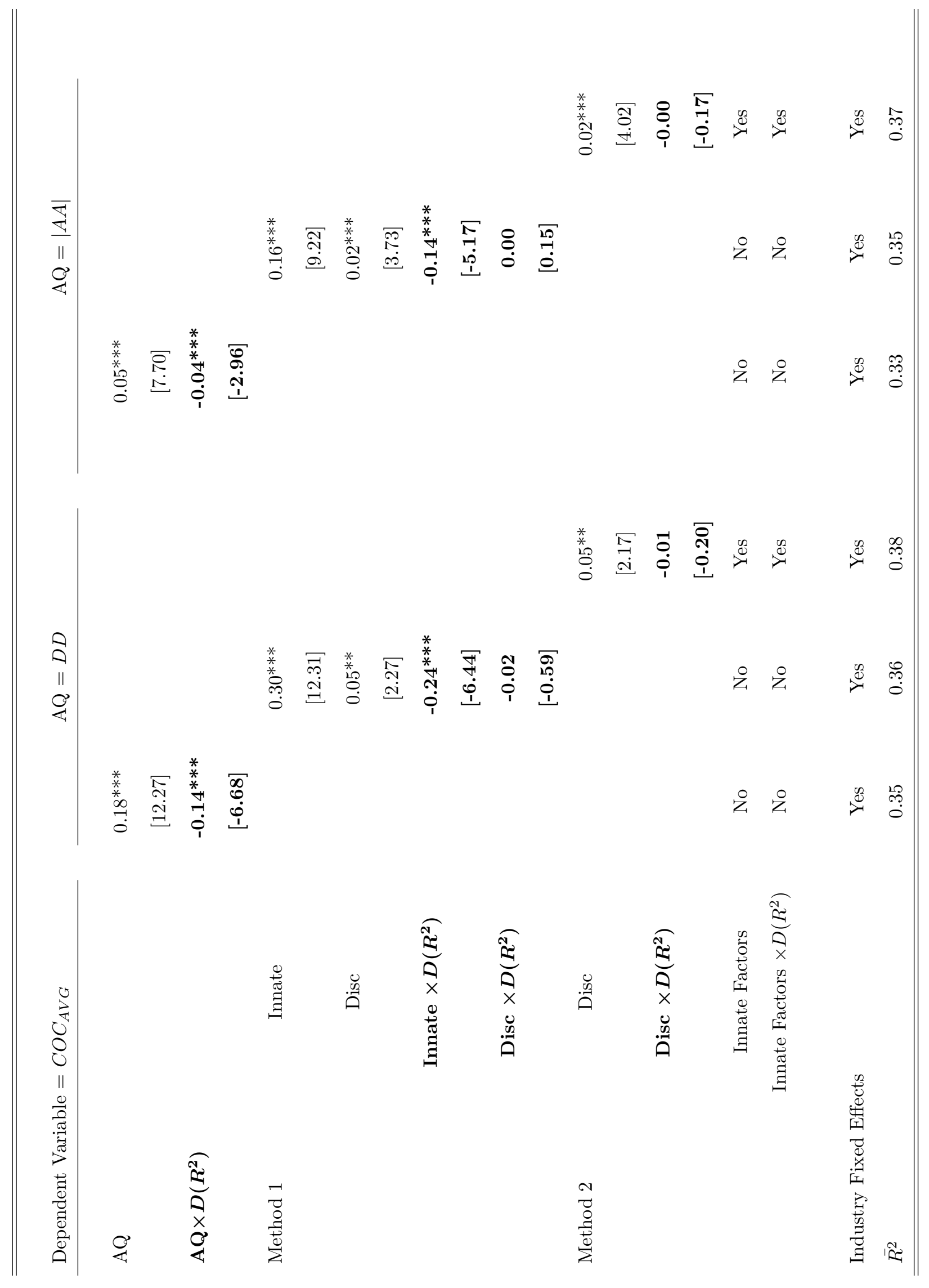




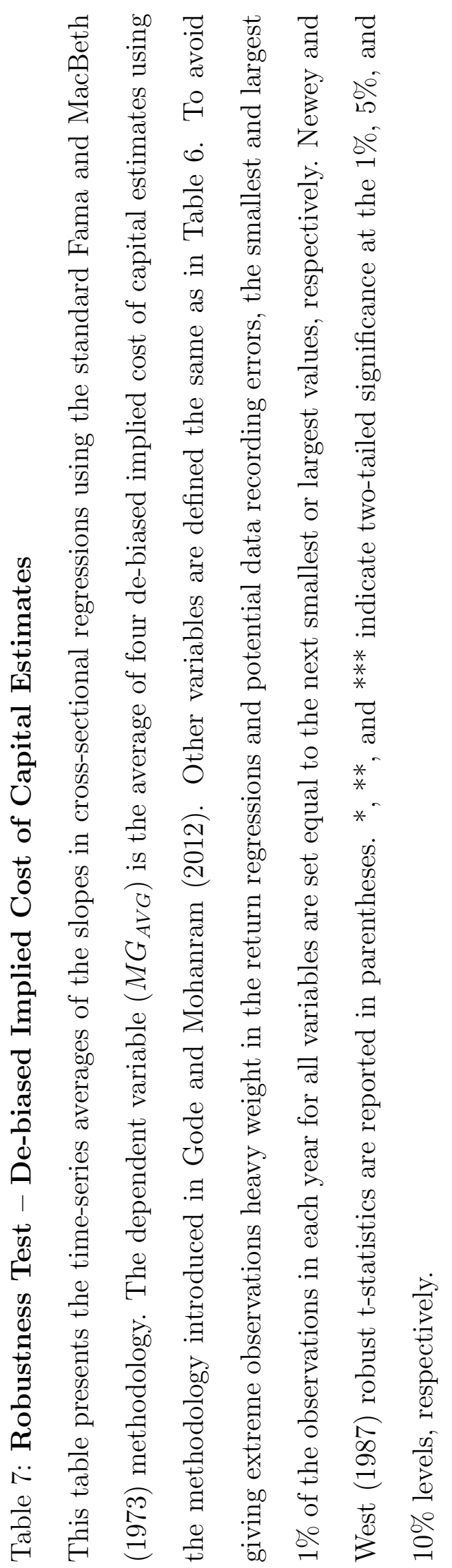




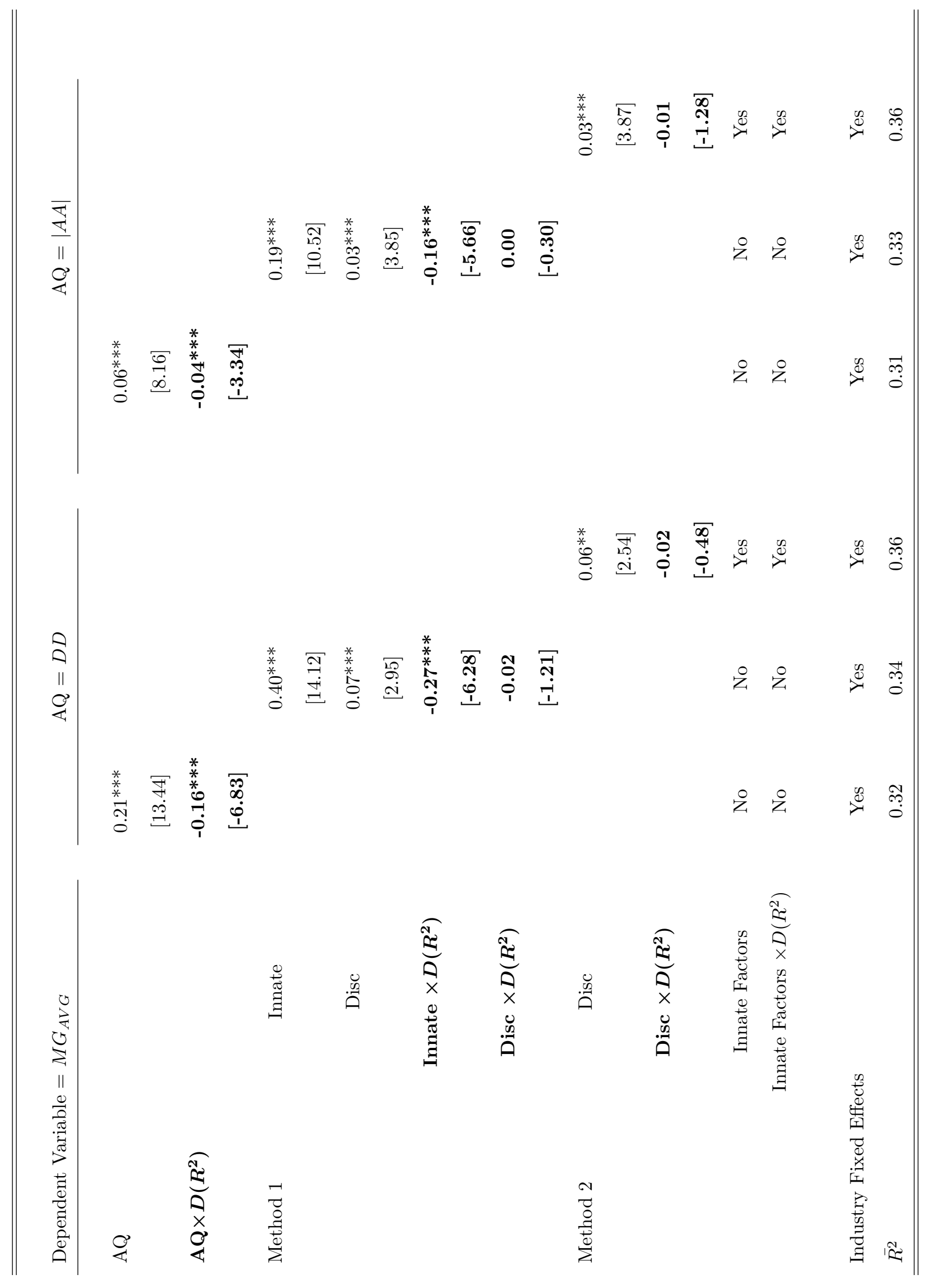




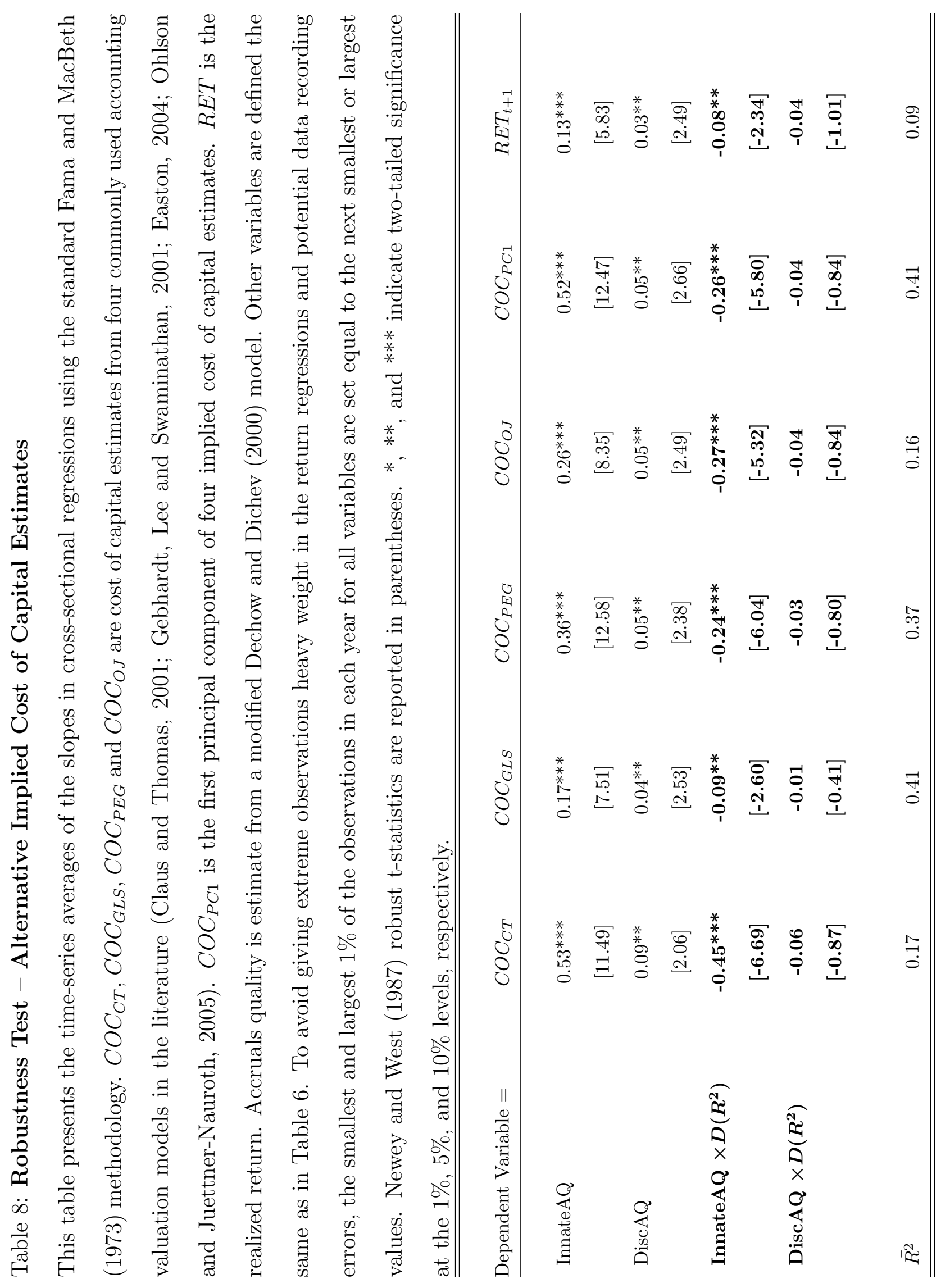




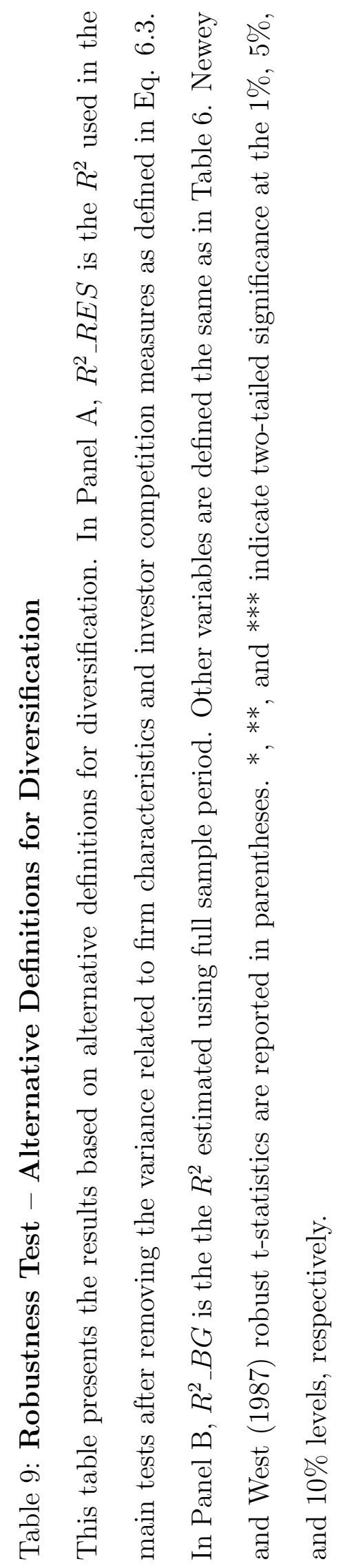




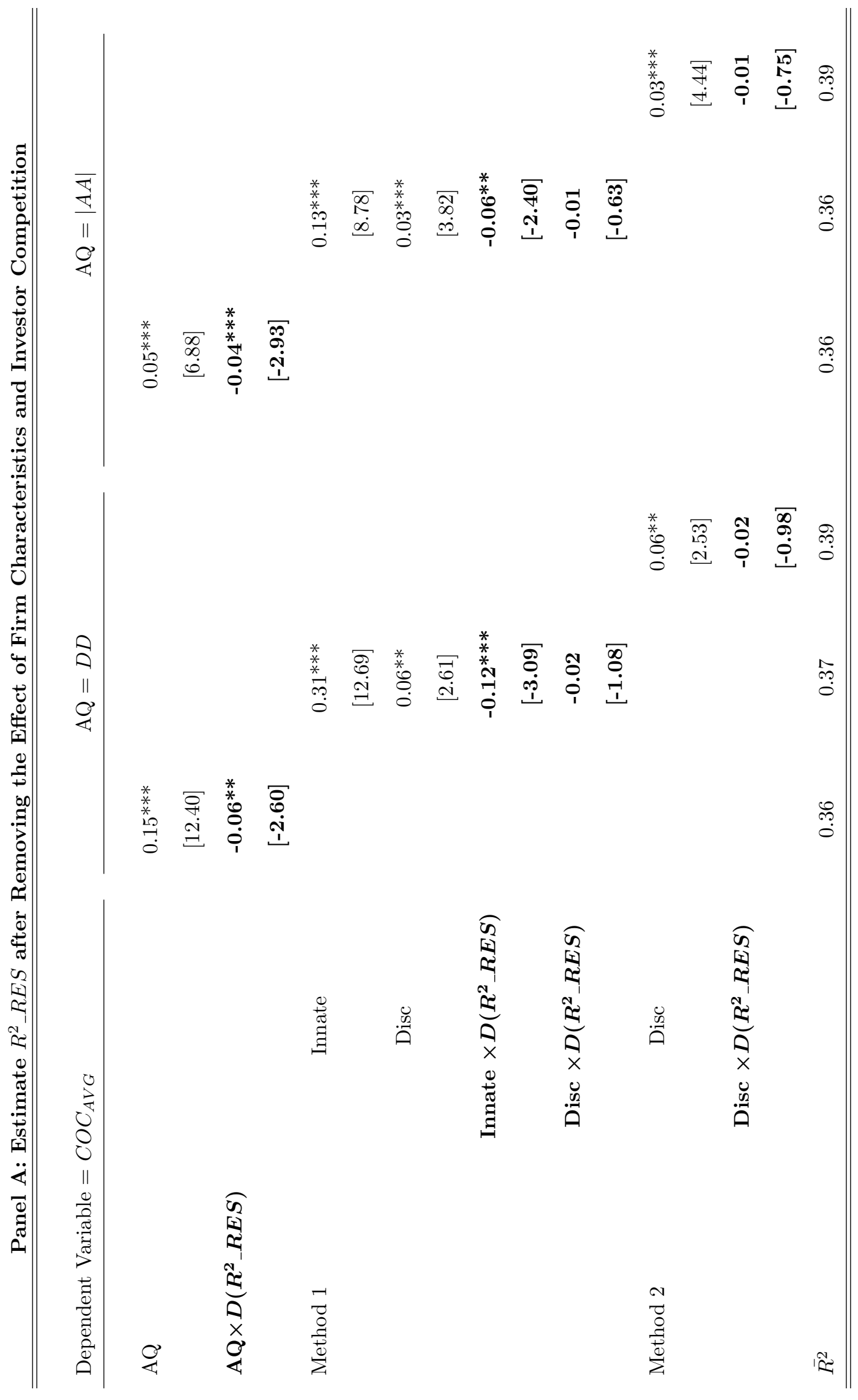




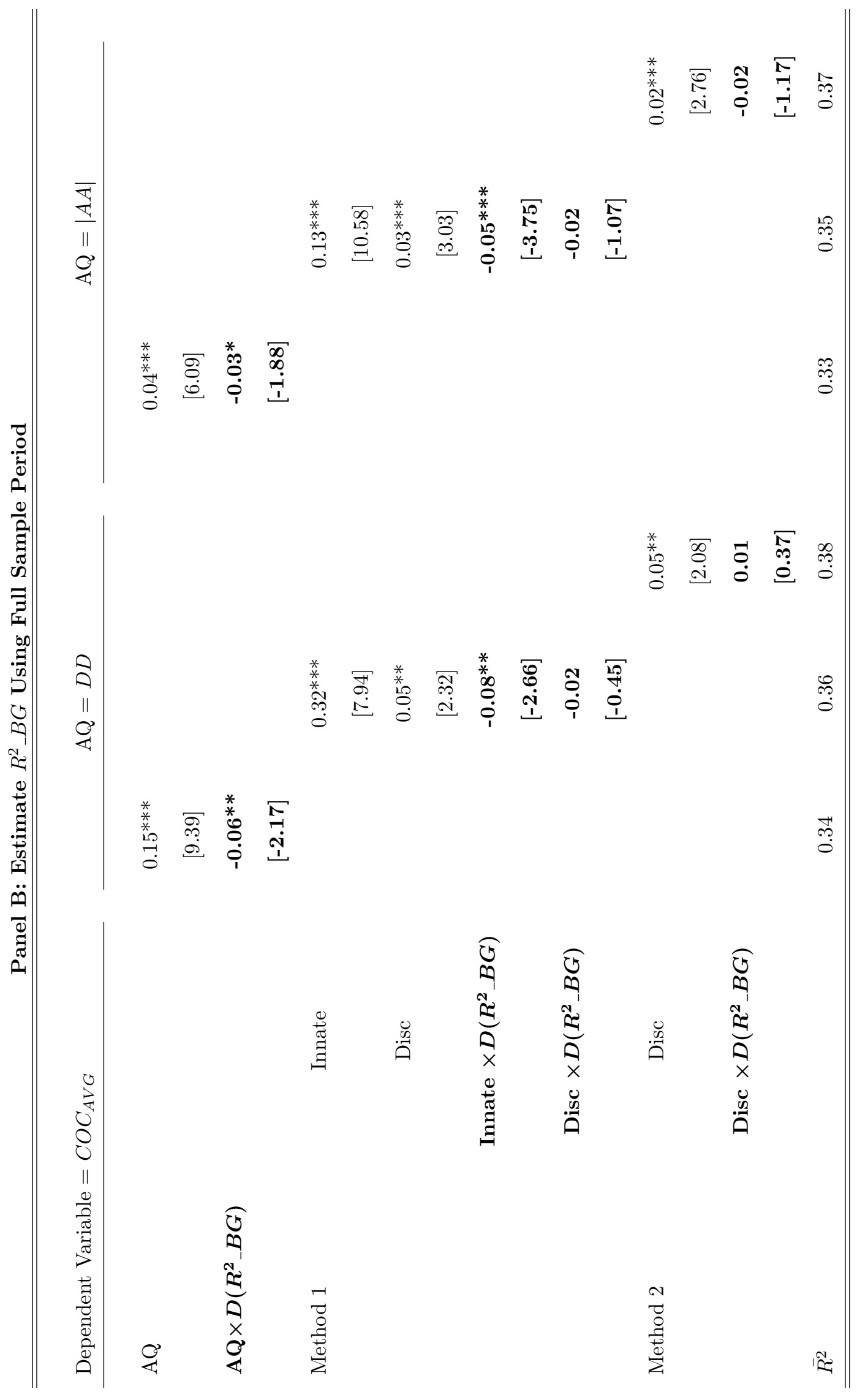

